\title{
Constraining the aerosol influence on cloud fraction
}

\author{
Article \\ Published Version
}

Gryspeerdt, E., Quaas, J. and Bellouin, N. (2016) Constraining the aerosol influence on cloud fraction. Journal of Geophysical Research, 121 (7). pp. 3566-3583. ISSN 0148-0227 doi: https://doi.org/10.1002/2015JD023744 Available at https://centaur.reading.ac.uk/62322/

It is advisable to refer to the publisher's version if you intend to cite from the work. See Guidance on citing.

To link to this article DOI: http://dx.doi.org/10.1002/2015JD023744

Publisher: American Geophysical Union

All outputs in CentAUR are protected by Intellectual Property Rights law, including copyright law. Copyright and IPR is retained by the creators or other copyright holders. Terms and conditions for use of this material are defined in the End User Agreement.

\section{www.reading.ac.uk/centaur}

\section{CentAUR}

Central Archive at the University of Reading

Reading's research outputs online 


\section{Journal of Geophysical Research: Atmospheres}

\author{
RESEARCH ARTICLE \\ 10.1002/2015JD023744 \\ Key Points: \\ - A new technique is used to inves- \\ tigate causality in aerosol-cloud \\ interactions \\ - The strength of the aerosol optical \\ depth-cloud fraction relationship is \\ significantly reduced \\ - Cloud sensitivity remains positive \\ globally. The magnitude of the \\ aerosol effect is still uncertain
}

Supporting Information:

- Supporting Information S1

Correspondence to:

E. Gryspeerdt,

edward.gryspeerdt@uni-leipzig.de

\section{Citation:}

Gryspeerdt, E., J. Quaas, and N. Bellouin (2016), Constraining the aerosol influence on cloud fraction, $J$. Geophys. Res. Atmos., 121, 3566-3583, doi:10.1002/2015JD023744.

Received 2 JUN 2015 Accepted 10 MAR 2016 Accepted article online 17 MAR 2016 Published online 14 APR 2016

○2016. American Geophysical Union. All Rights Reserved.

\section{Constraining the aerosol influence on cloud fraction}

\author{
E. Gryspeerdt ${ }^{1}$, J. Quaas ${ }^{1}$, and N. Bellouin ${ }^{2}$ \\ ${ }^{1}$ Institute for Meteorology, Universität Leipzig, Leipzig, Germany, ${ }^{2}$ Department of Meteorology, University of Reading, \\ Reading, UK
}

\begin{abstract}
Aerosol-cloud interactions have the potential to modify many different cloud properties. There is significant uncertainty in the strength of these aerosol-cloud interactions in analyses of observational data, partly due to the difficulty in separating aerosol effects on clouds from correlations generated by local meteorology. The relationship between aerosol and cloud fraction (CF) is particularly important to determine, due to the strong correlation of CF to other cloud properties and its large impact on radiation. It has also been one of the hardest to quantify from satellites due to the strong meteorological covariations involved. This work presents a new method to analyze the relationship between aerosol optical depth (AOD) and CF. By including information about the cloud droplet number concentration (CDNC), the impact of the meteorological covariations is significantly reduced. This method shows that much of the AOD-CF correlation is explained by relationships other than that mediated by CDNC. By accounting for these, the strength of the global mean AOD-CF relationship is reduced by around $80 \%$. This suggests that the majority of the AOD-CF relationship is due to meteorological covariations, especially in the shallow cumulus regime. Requiring CDNC to mediate the AOD-CF relationship implies an effective anthropogenic radiative forcing from an aerosol influence on liquid $\mathrm{CF}$ of $-0.48 \mathrm{~W} \mathrm{~m}^{-2}\left(-0.1\right.$ to $\left.-0.64 \mathrm{~W} \mathrm{~m}^{-2}\right)$, although some uncertainty remains due to possible biases in the CDNC retrievals in broken cloud scenes.
\end{abstract}

\section{Introduction}

Many atmospheric aerosols have the ability to act as cloud condensation nuclei (CCN), influencing the cloud droplet number concentration (CDNC). At a constant cloud water content, this can lead to an increase in the cloud albedo, resulting in a negative radiative forcing [Twomey, 1977]. It has been hypothesized that this increase in CDNC may result in an increase in cloud fraction (CF) by reducing precipitation formation efficiency [Albrecht, 1989]. It is also possible that a reduction in cloud droplet size may also lead to increased evaporation and a reduction in CF [Ackerman et al., 2000; Small et al., 2009]. It is particularly important to understand the relationship between satellite-retrieved aerosol optical depth (AOD, used as a proxy for CCN) and CF. As many cloud properties are strongly correlated to CF, the AOD-CF relationship can generate correlations between AOD and other cloud properties, even in the absence of an aerosol influence on these properties [Gryspeerdt et al., 2014a]. Unfortunately, the multiple competing effects, along with the difficulty of disentangling an aerosol effect from the influence of meteorology, make the influence of aerosol on CF particularly uncertain [Tao et al., 2012]. Aerosol influences on cloud properties are one of the largest uncertainties in the anthropogenic climate forcing [Boucher et al., 2013].

Satellite studies of aerosol-cloud interactions have been able to generate estimates of the influence of aerosol on cloud albedo [Quaas et al., 2008]. However, although strong correlations between AOD and CF have been observed in many different locations and with many different instruments [Sekiguchi et al., 2003; Kaufman et al., 2005; Kaufman and Koren, 2006; Loeb and Schuster, 2008; Koren et al., 2008, 2010a; Kaufman et al., 2005, 2005; Dey et al., 2011; Small et al., 2011; Yuan et al., 2011] the magnitude of the aerosol influence on CF is still highly uncertain. Studies using general circulation models indicate that aerosol hygroscopic growth is responsible for a large part of the positive AOD-CF relationship [Quaas et al., 2010; Grandey et al., 2013]; cloud resolving models indicate that aerosols may have a very small [Stevens and Seifert, 2008] or even slightly negative [Xue and Feingold, 2006; Seifert et al., 2015] influence on the CF of shallow cumulus clouds. Errors in the retrieval of both cloud [Brennan et al., 2005] and aerosol properties [Zhang et al., 2005; Várnai and Marshak, 2009, 2011] can generate correlations between aerosol and cloud properties, which might be misinterpreted as an aerosol influence on clouds [Yuan et al., 2008]. Other effects, such as the impact of clouds on aerosol properties and atmospheric convergence, have also been shown to generate an AOD-CF 
relationship and together these effects may account for $75 \%$ of the strength of the total relationship [Jeong and $L i, 2010]$. The effect of these confounding variables, such as relative humidity and convergence, results in "meteorological covariations" of aerosol and cloud properties, making it difficult to derive an estimate of the total aerosol indirect effect from observations alone.

Several previous studies have used observational techniques to constrain the aerosol influence on CF [Kaufman et al., 2003; Mauger and Norris, 2007; Meskhidze et al., 2009; Koren et al., 2010a; Small et al., 2011; Gryspeerdt et al., 2014b]. These techniques usually reduce the influence of meteorological covariations by using reanalysis data to account for the controlling variables. As meteorological covariations tend to increase the correlation between $A O D$ and $C F$, this method of accounting for meteorology tends to reduce the observed strength of the AOD-CF relationship and would be expected to produce an upper bound on the magnitude of the influence of aerosols on CF.

Explicitly accounting for meteorological covariations using reanalysis data suffers from some significant uncertainties. Reanalysis data are not sufficiently representative of the real atmosphere to completely remove the influence of meteorological covariation on the AOD-CF relationship. In particular the relative humidity shows a strong small- to mesoscale variability that is highly important for the aerosol swelling and cloud formation and cannot be constrained by reanalysis products that are available at scales on the order of tens of kilometers [Boucher and Quaas, 2012]. For example, Koren et al. [2010a] find cloud fractions of up to 90\% for relative humidities constrained to be less than $25 \%$. This implies that these meteorological covariations are likely to still exist (although with a reduced magnitude), even if attempts are made to remove them using reanalysis data.

The difficulty of determining causation purely from observations is not new. Ideally, a series of experiments or randomized controlled trials would be used. However, for many problems, such as those in economics, public health or atmospheric science, such an experiment is often not possible. Previous studies have shown that AOD is able to predict the development of CF [Meskhidze et al., 2009; Gryspeerdt et al., 2014b], demonstrating a lagged correlation necessary for "Granger causality" [Granger, 1969]. However, as humidity also influences the development of $C F$, this method does not conclusively demonstrate an influence of aerosol on CF and still relies on the accuracy of reanalysis products.

To reduce the reliance on reanalysis products, the retrieved cloud droplet number concentration (CDNC) is introduced as a third variable on the chain of causality between AOD and CF, breaking the AOD-CF relationship into two separate relationships. As CDNC is thought to be relatively independent of humidity (compared to AOD and CF), this enables the AOD-CF relationship to be investigated with a reduced influence of meteorological covariations. Given the nonlinearities expected in this system, joint histograms are used to keep as much information as possible when considering the possible aerosol influence on CF. This then enables an improved estimate of the relationship between AOD and CF in the absence of meteorological covariations to be determined.

\section{Methods}

\subsection{Calculus of Actions}

The influence of meteorological covariations on the AOD-CF relationship obscures the impact of a change in aerosol properties on CF. In order to account for the influence of these meteorological covariations, it is important to consider the difference between observations and actions.

The relationship between AOD and CF can be considered as in Figure $1 \mathrm{a}$. In this diagram, $M$ is a confounding factor that influences both the AOD and CF. It could represent the influence of aerosol hygroscopic growth or other meteorological effects, the exact form it takes is not important. If there were no confounding factors (there was no influence of $\mathrm{M}$ on $\mathrm{AOD}$ or $\mathrm{CF}$ ), then an observation of the conditional probability $P\left(C F=f_{c} \mid C C N=N_{C C N}\right)$ would be enough to determine the effect of setting the CCN equal to $N_{C C N}$. The probability of observing a CF of $f_{c^{\prime}}$ given that the $C C N$ has been set to $N_{\mathrm{CCN}}$ is written as $P\left(C F=f_{c} \mid \operatorname{do}\left(\mathrm{CCN}=N_{\mathrm{CCN}}\right)\right)$, using the notation of Pearl [1994] to indicate the consequences of an action.

The use of AOD as a CCN proxy is well established [Andreae, 2009], but it is an imperfect measure of CCN due to the impact of aerosol humidification but also due to uncertainties in vertical distribution [Costantino and Bréon, 2010]. Although there is variation by type of aerosol, there is a much closer relationship between 

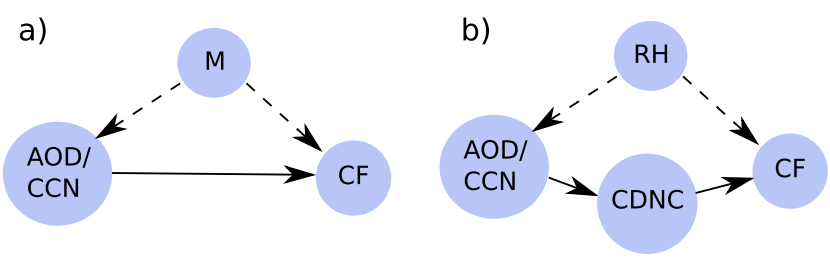

Figure 1. (a) A simple system with an unknown confounding factor $M$ that modifies the probabilities of the AOD and the $\mathrm{CF}$. (b) Considering the meteorology to be primarily relative humidity $(\mathrm{RH}), \mathrm{CDNC}$ is included to mediate the influence of AOD on CF. CDNC is independent of RH.

the aerosol dry extinction coefficient and CCN than between AOD and CCN [Liu and Li, 2014; Shinozuka et al., 2015]. This suggests that if aerosol humidification can be accounted for, AOD would improve as a CCN proxy.

If there is a confounding factor $(M)$ that is able to influence $P\left(\mathrm{CF}=f_{c}\right), P\left(\mathrm{AOD}=\tau_{a}\right)$, and $P\left(\mathrm{CF}=f_{c} \mid \mathrm{AOD}=\right.$ $\left.\tau_{a}\right)$, then the observed probability $P\left(f_{c} \mid \tau_{a}\right)$ is no longer equal to the outcome of an action $\left(P\left(f_{c} \mid \operatorname{do}\left(\tau_{a}\right)\right)\right)$. If a good model exists for the influence of $M$ on the CF and AOD, then its influence could be accounted for with sufficiently accurate measurements of $M$. Multiple regression [Kaufman et al., 2003] or stratification by $M$ [Koren et al., 2005] could be then used to remove the influence of $M$. However, these methods will not be able to account for the influence of $M$, if the measurements of $M$ are not accurate enough. For example, binning by reanalysis relative humidity at a scale of tens of kilometers is not able to account for the influence of aerosol humidification on the AOD-precipitation relationship [Boucher and Quaas, 2012].

By introducing a variable that is independent of $M$ along the causal pathway between $A O D$ and $C F$, it is possible to determine $P\left(f_{c} \mid \mathrm{do}\left(\tau_{a}\right)\right)$ using only observed probabilities in the presence of an unknown or unmeasurable confounding factor $M$ (Figure 1b). As the hypothesized cause-effect relationship between aerosol and CF involves an increase in CCN causing an increase in CDNC $\left(N_{d}\right)$, which then influences cloud properties such as $\mathrm{CF}$, this make CDNC a good candidate for the mediating variable.

Although the CDNC is not independent of meteorology [Bennartz, 2007] and the accuracy of the CDNC retrieval depends on the adiabaticity of the cloud [Zuidema and Painemal, 2009; Merk et al., 2015], it is not known to depend on the relative humidity in the same manner as AOD or CF, as it is more strongly controlled by the aerosol population and the in cloud updraft rather than the large-scale relative humidity. As humidity exerts a large confounding influence over the AOD-CF relationship, using CDNC as a mediating variable removes a large part of the confounding influence of meteorology. As it removes the influence of any link between $A O D$ and $C F$ that does not also influence the CDNC, it also removes the confounding impact of wind speed, although it excludes aerosol-cloud interactions that do not modify the CDNC, such as the semidirect effect.

Using the rules for manipulating these causal diagrams outlined in Pearl [1994], it is possible to determine $P\left(f_{c} \mid \mathrm{do}\left(\tau_{a}\right)\right)$. For this simple system, in Figure $1 \mathrm{~b}$,

$$
P\left(f_{c} \mid \operatorname{do}\left(\tau_{a}\right)\right)=\sum_{N_{d}} P\left(f_{c} \mid N_{d}\right) \times P\left(N_{d} \mid \tau_{a}\right)
$$

This result requires that the diagram (Figure $1 \mathrm{~b}$ ) represents all the relevant parts of the system and the links between them. The influence of additional meteorological factors on either of the AOD-CDNC or the CDNC-CF pairs would require the inclusion of additional confounding factors, as would retrieval errors generating a relationship between the CDNC and the CF. The impact of these additional factors is considered in the discussion section, but the setup proposed here is sufficient for accounting for the influence of relative humidity on the AOD-CF relationship.

The conditional probabilities required can be determined from joint histograms of the relevant variables. For example, $P\left(f_{c} \mid N_{d}\right)$ (the probability of finding a certain CF given that a certain CDNC has been observed) is the joint histogram of $f_{c}$ and $N_{d}$ for a specific location or region, normalized by the occurrence of $N_{d}$ (such that the probabilities of $P\left(f_{c} \mid N_{d}\right)$ sum to one for each value of $\left.N_{d}\right)$. The multiplication and summation of these two conditional probability distributions are conceptually similar to multiplying the slopes of the AOD-CDNC and the CDNC-CF regressions. However, the use of conditional probability distributions retains more information about the nonlinearity of the relationships, allowing a nonlinear relationship between AOD and CF. 


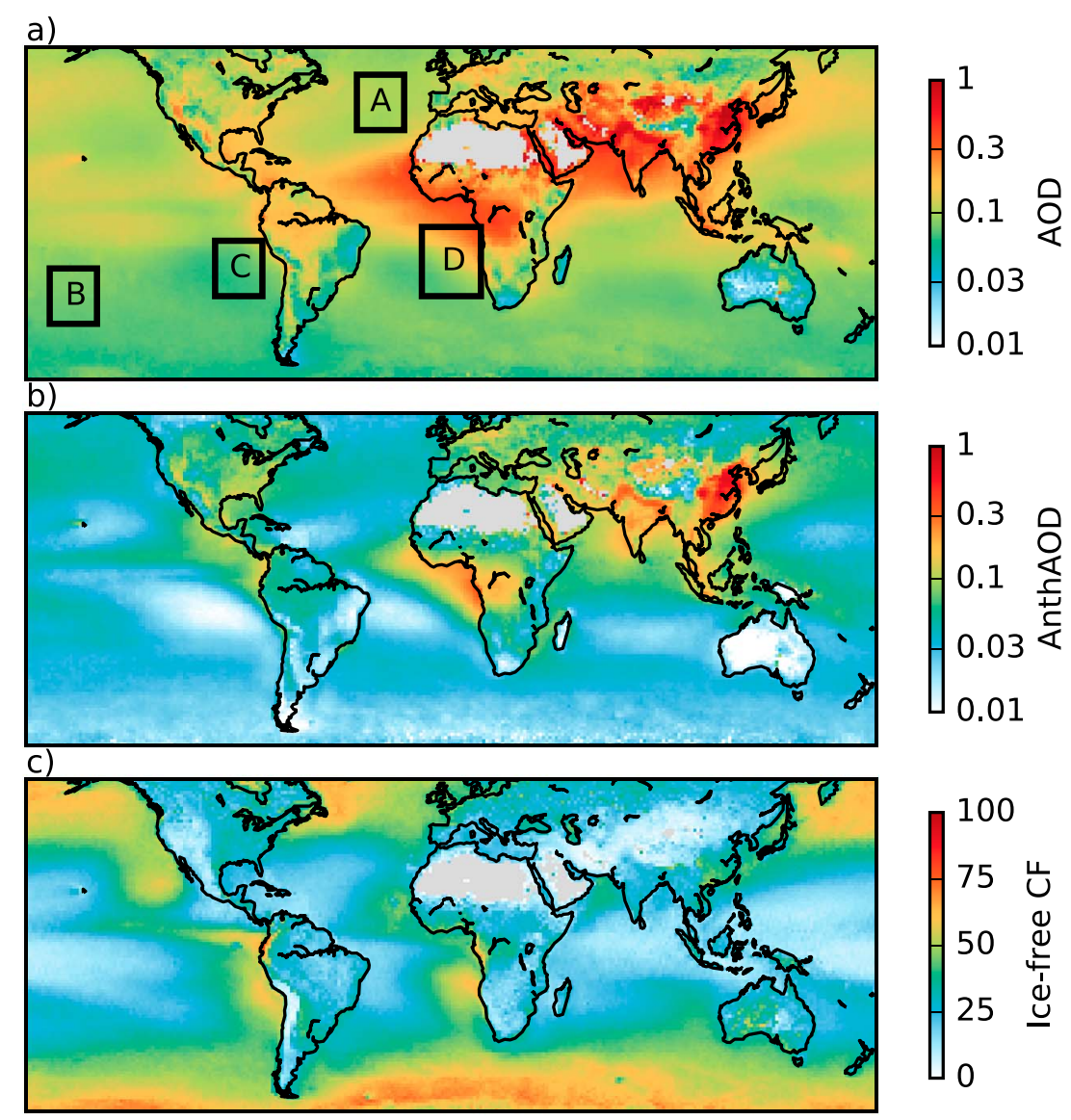

Figure 2. (a) The mean MODIS AOD between 2003 and 2013 and (b) the anthropogenic AOD, determined from the MACC anthropogenic AOD fraction and MODIS AOD retrievals. Note the log color scale. (c) The mean MODIS liquid CF in regions with zero ice cloud cover. The boxes indicate the regions used throughout this work.

This allows the results of an experiment where the AOD/CCN is modified and the CF is observed to be determined independent of the confounding factor $M$.

\subsection{Data}

Cloud [Platnick et al., 2003] and aerosol [Levy et al., 2013] data from the moderate resolution imaging spectrometer (MODIS) onboard the Aqua satellite are used in this work. All of the data used in this study is from the $1^{\circ}$ by $1^{\circ}$ resolution collection 6, daily average level 3 product. Data from the period 2003-2013 are used in this study, in the region $60^{\circ} \mathrm{N}$ to $60^{\circ} \mathrm{S}$. The aerosol product used is the "Optical_Depth_Land_and_Ocean_Mean" at $550 \mathrm{~nm}$. As with many satellite studies, the aerosol and cloud property retrievals are not perfectly colocated, as the AOD is only retrieved in clear skies. However, at a $1^{\circ}$ by $1^{\circ}$ resolution, many grid boxes include both aerosol and cloud retrievals, these are considered to be coincident in this analysis. This may create a bias in strongly precipitating scenes where the below-cloud aerosol is affected by precipitation, although in weakly precipitating locations the influence of wet scavenging on the aerosol is not as strong. Previous work has suggested that in some situations, the aerosol in neighboring cloud-free regions may be more representative of the aerosol that is interacting with a cloud than the below-cloud aerosol, justifying the colocation assumption made here [Gryspeerdt et al., 2015]. To increase the number of available high CF pixels used in this analysis, the AOD is interpolated into grid cells with missing data as long as they have a neighbor containing an AOD retrieval (following Koren et al. [2012]). This increases the number of available pixels by approximately $25 \%$, primarily over land, although in the high CF stratocumulus regions, up to $30 \%$ of grid cells make use of interpolated aerosol data. Only locations with an AOD, CF, and CDNC retrieval are kept for this analysis.

To determine the CF, the "Cloud_Fraction_Combined" variable is used, which is the fraction of points where a successful cloud retrieval has been performed. This is lower than the MODIS cloud mask CF but has a smaller chance of being misclassified heavy aerosol rather than cloud [Hubanks et al., 2008]. It also varies across the 
full range of $C F(0-100 \%)$ with varying $C D N C$, unlike the cloud mask $C F$, which does not often fall below $30 \%$ in grid boxes where a CDNC retrieval exists. This retrieval CF is also approximately linearly related to the cloud albedo [Bender et al., 2011], both simplifying the forcing calculation and improving its accuracy. To reduce the possible impact of changes in the ice $C F$, the $C F$ is only used in grid boxes where the ice $C F$ is zero (the ice-free liquid CF-Figure 2c). To estimate the cloud droplet number concentration $\left(N_{d}\right)$, the MODIS cloud top effective radius $\left(r_{e}\right)$ and cloud optical thickness $\left(\tau_{c}\right)$ are used together with the adiabatic approximation [Brenguier et al., 2000]. In this equation (equation (2)), $N_{d}$ is the CDNC and $\gamma=1.37 \times 10^{-5} \mathrm{~m}^{-\frac{1}{2}}$ [Quaas et al., 2006]. A temperature-dependent condensation rate is applied following Bennartz [2007], using a moist adiabatic lapse rate for the change in temperature with height and an assumed pressure of $850 \mathrm{hPa}$. As an estimate of the cloud base temperature, the maximum MODIS cloud top temperature within a $1^{\circ}$ by $1^{\circ}$ grid box is used to provide the temperature for the condensation rate.

$$
N_{d}=\gamma f(T) \tau_{c}^{\frac{1}{2}} r_{e}^{-\frac{5}{2}}
$$

where $f(T)=0.0192 T-4.293$, with a temperature in K. This calculation is done using the optical depth/cloud top effective radius joint histogram in the level 3 MODIS product. Retrievals with an optical depth less than 4 or an effective radius less than $4 \mu \mathrm{m}$ are excluded as these retrievals are less reliable [Nakajima and King, 1990]. These data are then used to generate the joint probability histograms required by the method outlined in the previous section. The global calculations are performed by aggregating data over $2^{\circ}$ by $2^{\circ}$ regions to ensure that the joint histograms are populated enough that they contain probability distributions. Having too little data in each grid box can bypass the CDNC mediation.

To investigate the implied radiative forcing associated with the AOD-CF relationship, the daily single scatter footprint (SSF) product from the Clouds and the Earth's Radiant Energy System (CERES) instrument at a $1^{\circ}$ by $1^{\circ}$ resolution is used [Wielicki et al., 1996] over the period 2003-2013. The relationship between clear sky $\left(\left(\mathrm{SW}_{\mathrm{cs}}\right)\right.$ and overcast ( $\left(\mathrm{SW}_{\mathrm{cld}}\right)$ top of atmosphere (TOA) shortwave $(\mathrm{SW})$ radiation is used to calculate the local SW cloud forcing as a function of CF in grid boxes with no ice cloud coverage $\left(\left(S W_{c l d}-S W_{c s}\right)_{n i}\right)$. This is then used to calculate the implied radiative forcing following equation (3), where the subscript "ni" indicates a calculation being performed only when a $1^{\circ}$ by $1^{\circ}$ grid box is free of ice cloud.

$$
\Delta \mathrm{SW}=\left(1-f_{\text {ice }}\right)\left(\mathrm{SW}_{\mathrm{cld}}-\mathrm{SW} \mathrm{CS}_{\mathrm{ni}} \frac{d f_{\text {liq-ni }}}{d \ln \tau_{a}}\left(\ln \tau_{a}-\ln \tau_{a}^{\mathrm{nat}}\right) .\right.
$$

As this study ignores possible aerosol influences on ice clouds, the factor $\left(1-f_{\text {ice }}\right)$ accounts for ice cloud masking of changes to the liquid cloud amount. The monitoring atmospheric composition and climate (MACC) reanalysis dataset [Morcrette et al., 2011] is used to determine the anthropogenic aerosol fraction over the period 2003-2013. This dataset assimilates MODIS AOD retrievals into the European Centre for Medium-Range Weather Forecasts (ECMWF)-integrated forecast system, creating a speciated aerosol product every $3 \mathrm{~h}$. This is then interpolated to 13:30 local solar time to approximate the overpass time of the Aqua satellite. The anthropogenic fraction of Bellouin et al. [2013] is multiplied by the MODIS AOD (Figure 2a) to determine the anthropogenic AOD (Figure $2 b$ ) and hence the natural AOD $\left(\tau_{a}^{\text {nat }}\right)$. The MACC speciated product is also used to investigate the relationship of different aerosol types with the CF. A second anthropogenic aerosol product, derived from global climate/aerosol models (MACv2, updated from Kinne et al. [2013]), is used to provide further information on the uncertainty associated with the aerosol composition of the preindustrial atmosphere.

The European Centre for Medium-Range Weather Forecasts (ECMWF) reanalysis ERA-Interim [Dee et al., 2011] is used to calculate low troposphere static stability (LTS), as the difference in potential temperature between 700 and $1000 \mathrm{hPa}$ (similar to Klein and Hartmann [1993]). The LTS is used to separate different cloud regimes in this work, low LTS regions have been shown to have more shallow cumulus-like clouds, with high LTS regions typically including more stratocumulus-like clouds.

\section{Results}

\subsection{Regional Results}

Due to the strong regional variations in aerosol and cloud properties, the relationship between AOD, CDNC, and CF is investigated in several different regions. Four regions (outlined in Figure 2a) are chosen for analysis, two tropical stratocumulus regions (one at the center of the Namibian stratocumulus deck $-5-30^{\circ} \mathrm{S}$, 

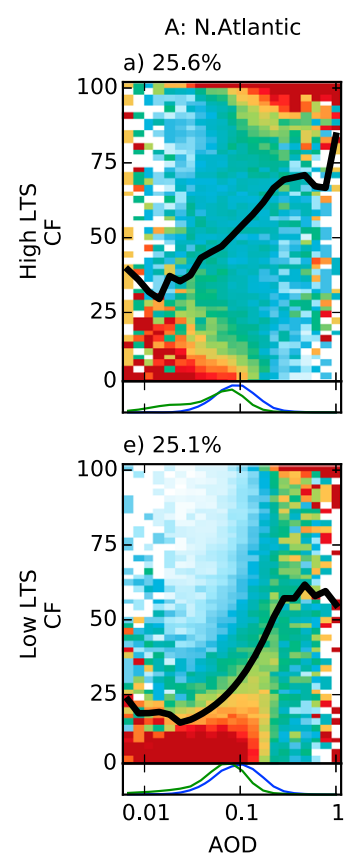

B: S. Pacific b) $15.1 \%$

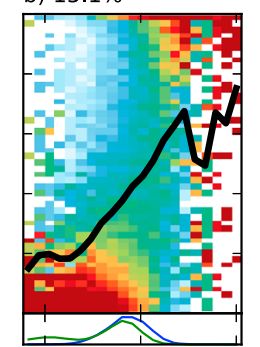

f) $32.2 \%$

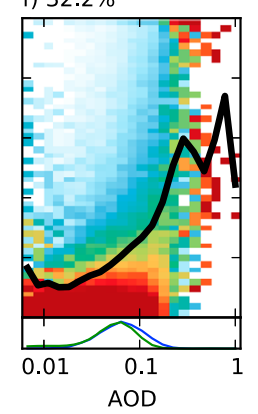

C: Peruvian Sc. Edge c) $80.6 \%$

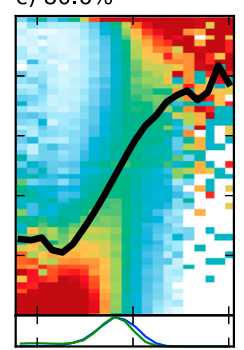

g) $2.7 \%$

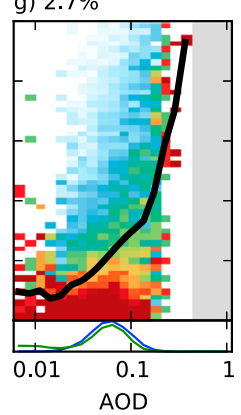

D: Namibian Sc. d) $69.1 \%$

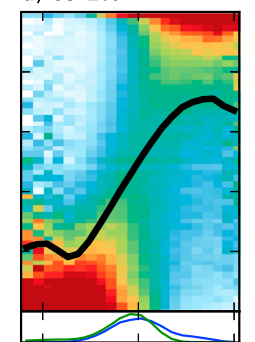

$\frac{0}{\circ} \pi_{3.0}^{5.0}$

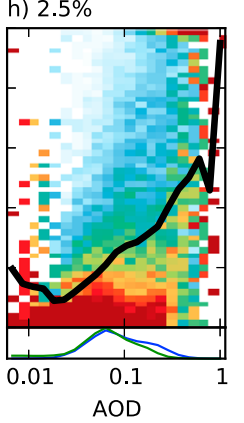

Figure 3. The probability of finding a specified cloud fraction $\left(C F=f_{c}\right)$, given that a certain aerosol optical depth $\left(\mathrm{AOD}=\tau_{a}\right)$ has been observed for different regions and different LTS regimes $\left(P\left(f_{c} \mid \tau_{a}\right)\right)$. The columns are normalized so that each sums to $100 \%$. The frequency of occurrence of the LTS regime is shown in the top left of each subplot. The thick black line in each plot shows the mean $\mathrm{CF}\left(\bar{f}_{c} \mid \tau_{a}\right)$. The histogram under each plot shows the probability distribution function of AODs retrieved in each region (blue present day, green natural; from the MACC reanalysis). These plots contain data from the collection 6 Aqua MODIS level 3 product over the period 2003-2013 inclusive, only using pixels with zero ice cloud fraction and a retrieval of AOD, CF, and CDNC. The LTS data are from ERA-Interim.

$12.5^{\circ} \mathrm{W}-12.5^{\circ} \mathrm{E}$ and one at the edge of the Peruvian deck $-100-80^{\circ} \mathrm{W}, 10-30^{\circ} \mathrm{S}$ ) and two extratropical regions (one in the north Atlantic $-40-20^{\circ} \mathrm{W}, 30-50^{\circ} \mathrm{N}$ and one in the south Pacific $-170-150^{\circ} \mathrm{W}, 20-40^{\circ} \mathrm{S}$ ). Due to the varying possible relationships between aerosol and cloud properties, different cloud regimes are determined using the LTS. The high LTS population only includes pixels with an LTS above $18 \mathrm{~K}$ to separate out stratocumulus-like clouds in the tropics. The low LTS population includes only locations with an LTS less than $14 \mathrm{~K}$, selecting shallow cumulus-type clouds [Medeiros and Stevens, 2011].

As the method used in this paper relies on conditional probabilities, the joint histograms shown here are normalized so that each column sums to unity. Each bin then gives the probability of that state occurring, conditioned on the occurrence of the variable on the $x$ axis. The relationship between CF and AOD (CF|AOD) shown in Figure 3 displays a strong increase in CF with increasing AOD, as observed in earlier work. There is little variation between regions, although there is variation between the different cloud regimes. In the high LTS regime, there is a strong increase in CF with increasing AOD, for all values of AOD. There is some uncertainty around the $C F \mid A O D$ for the lowest and highest values of $A O D$, but these cases occur rarely (see the histograms under each plot).

In the low LTS regime, CF $\mid A O D$ increases strongly at high AOD values, remaining low for low AOD values. There is again a large uncertainty as the AOD rises above 0.5 , possibly due to the classification of high $A O D$ aerosol plumes as cloud [Brennan et al., 2005], which could generate an artificial increase in CF with increasing AOD. It is also important to note that the AOD distribution in each one of these locations and regimes varies. This is less important for the high LTS regime, where the increase in CF|AOD is approximately linear over the range of $A O D$ values that occur with nonnegligible probability. However, it can be important for the relationship between CF and AOD in the low LTS regime, where the mean AOD helps to determine the strength of the AOD-CF relationship locally.

As noted previously, much of this relationship is thought to be due to effects other than an aerosol influence on CF, such as meteorological covariation. This analysis is therefore repeated while requiring CDNC as a 

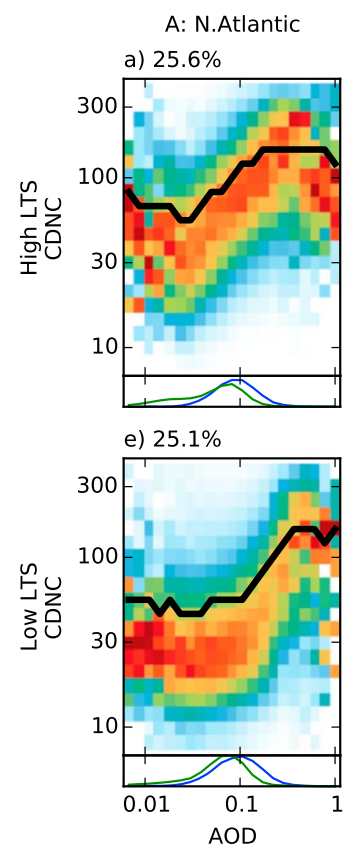

B: S. Pacific

b) $15.1 \%$

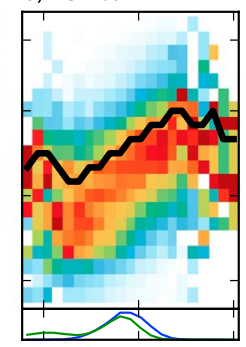

f) $32.2 \%$

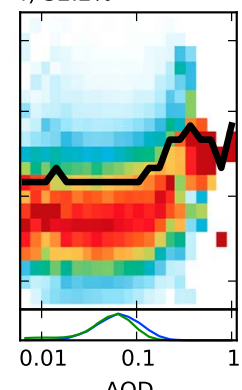

C: Peruvian Sc. Edge c) $80.6 \%$

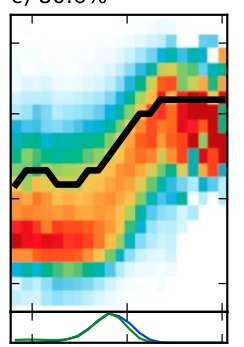

g) $2.7 \%$

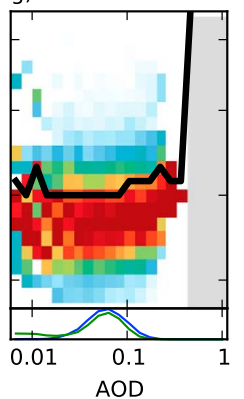

D: Namibian Sc.

d) $69.1 \%$

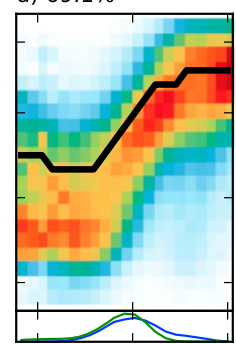

h) $2.5 \%$

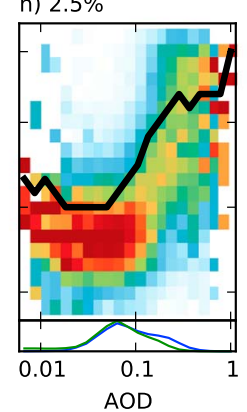

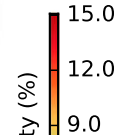

9.0

6.0

0.0

Figure 4. As Figure 3 , but showing the probability of a cloud droplet number concentration $\left(C D N C=N_{d}\right)$ retrieval given a certain $\mathrm{AOD}\left(=\tau_{a}\right)$ retrieval $\left(P\left(N_{d} \mid \tau_{a}\right)\right)$.

mediating factor to determine the AOD-CDNC-CF relationship. Considering the components of the AOD-CDNC-CF relationship separately allow the influence of meteorological covariations to be reduced.

As shown in previous work [Quaas et al., 2008; Grandey and Stier, 2010; Gryspeerdt and Stier, 2012], the CDNC increases with AOD in both regimes and in each region (Figure 4). However, this relationship is not linear. In general, there is little change in CDNC until the AOD approaches 0.03 . For the low LTS regime, the main increase comes above an AOD of 0.1. The low LTS regime in regions $B$ and C (S. Pacific and Peruvian stratocumulus) shows very weak relationships between CDNC and AOD. The reason for this is unclear, but by comparison to the other regions, it is likely due to the lack of high AOD situations encountered in these regions.

The nonlinearity of this relationship demonstrates the benefits of using the joint histogram approach over a simple linear regression between the two properties. Previous work has shown that there is a stronger sensitivity of CDNC to AOD in polluted regions [Grandey and Stier, 2010; Gryspeerdt and Stier, 2012]. Regional variations in aerosol type will play a role (see section 3.3) but Figure 4 suggests the nonlinearity of the AOD-CDNC relationship may also be important. As the sensitivity of CDNC to AOD variations increases with increasing AOD, this would result in a higher sensitivity in polluted regions.

Although there are differences between the regimes, care must be taken not to conclude too much from these plots. The difference between the regimes could be due to regime-dependent CDNC or AOD retrieval errors or perhaps a difference in updraft velocity changing the activated CCN fraction. The uncertainty in the microphysical retrieval is much larger for the cumuliform, more heterogeneous clouds in the low LTS regime [Zhang and Platnick, 2011], which could result in a difference in the CDNC-AOD relationship between the regimes. In cases with aerosol layers above cloud layers [which have been observed in region D [Costantino and Bréon, 2013], the aerosol can influence the retrieval of the cloud properties [Haywood et al., 2004], generating correlations between them. Care must also be taken when interpreting the nonlinearity, which although it could be due to a nonlinear relationship between AOD and CCN [Shinozuka et al., 2015], it could also be due to a nonlinearity in the relationship between "real" and retrieved CDNC. It is also possible that MODIS cannot accurately retrieve AOD below 0.05 , resulting in the nonlinearity observed at low AODs. The lack of AOD retrievals at very high and low AODs makes it difficult to clearly distinguish the properties of the $C D N C \mid A O D$ relationship in the two regimes. However, the final AOD-CDNC-CF relationship requires only that the relationship between "real" and retrieved CDNC is strictly monotonic and so it does not suffer from the same issues as the separate components of the relationship. 

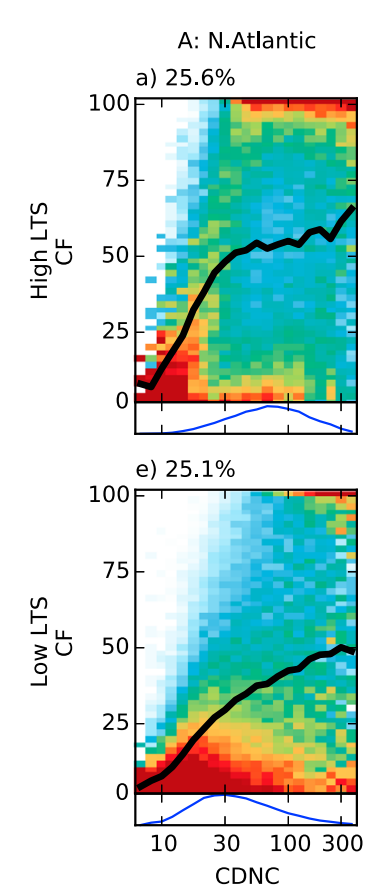

B: S. Pacific b) $15.1 \%$

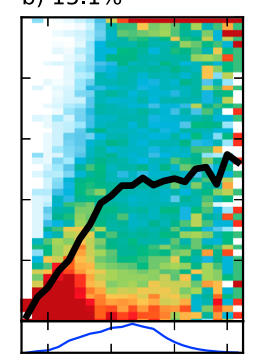

f) $32.2 \%$

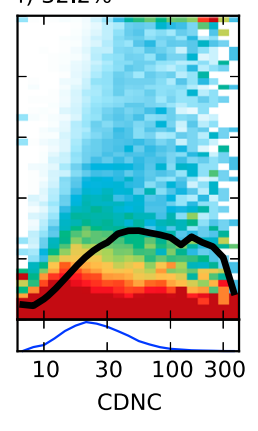

C: Peruvian Sc. Edge c) $80.6 \%$

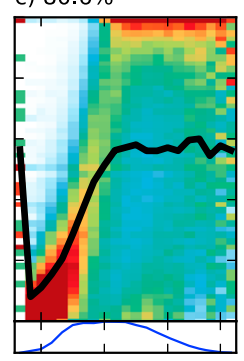

g) $2.7 \%$

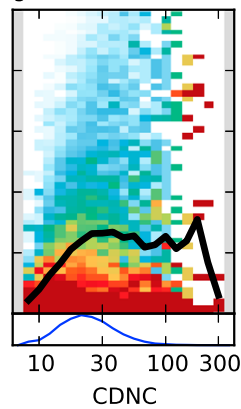

D: Namibian Sc. d) $69.1 \%$

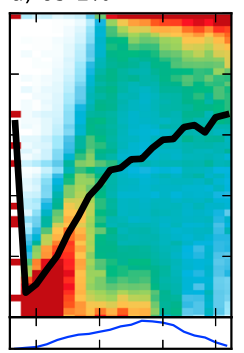

h) $2.5 \%$

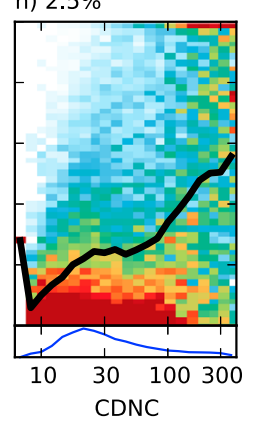

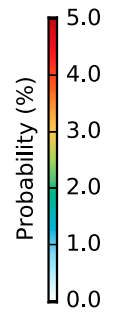

Figure 5. As Figure 3, but showing the probability of a CF retrieval given a certain CDNC retrieval (CF|CDNC). The histograms under each plot show the CDNC distribution.

The relationship between the CDNC and CF (CF|CDNC, Figure 5) shows a clearer difference between the high and the low LTS regimes although like the CDNC-AOD relationship, this should be treated with some caution. As expected, the high LTS regime generally has a higher CF (including clouds with a more stratocumulus-like character) and the low LTS regime includes shallow cumulus-like clouds with lower CF. In most of the regions, the retrieved CDNC is toward the lower end of the scale, below $100 \mathrm{~cm}^{-3}$, only the Namibian stratocumulus region (D) has a significant population of clouds with a retrieved CDNC greater than $100 \mathrm{~cm}^{-3}$. The variation in the CDNC between the regions in the high LTS regime comes from the sensitivity of CDNC to AOD being higher at higher AODs. At the lower AODs typically found in the low LTS regime, there is a smaller sensitivity of CDNC to AOD (Figure 4), resulting in much less variation in CDNC between the regions.

The CF in the high LTS regime displays a high sensitivity to CDNC at low values of CDNC, rising quickly as the CDNC increases. At higher values of CDNC, there is little sensitivity of CF to CDNC although there is still a large variation in CF. When the CDNC is above around $50 \mathrm{~cm}^{-3}$, changes in the CF have a much weaker relationship to changes in the CDNC. This would limit any aerosol influence on CF to clouds where the CDNC is high, due to the reduced sensitivity at high CDNC. The sensitivity at high CDNC appears to be partly due to a population of clouds with low CF but a CDNC of $20-50 \mathrm{~cm}^{-3}$, which keeps the mean CF low. These properties are much more consistent with the clouds in the low LTS regime, their occurrence in the high LTS regime may be due to the imperfect nature of LTS as a method for separating the cloud regimes [Nam et al., 2012].

The CF in the low LTS regime has a reduced sensitivity to CDNC, compared to the high LTS regime. Although all the regions show an increase in CF with increasing CDNC at low CDNCs, this effect is small and saturates relatively quickly. Some of the regions with more high CDNC retrievals ( $A$ and $D$ ) continue to show an increase in CF at high CDNCs whereas in the south Pacific, there appears to be a reduction in CF with increasing CDNC at high CDNCs. It is possible that the high CDNC behavior would become more similar between the regimes with an increase in the data at high CDNC, but it is unclear if the behavior of the low LTS regime at high CDNC is due to an influence of aerosol on shallow cumulus clouds or if it is due to the imperfect nature of using LTS from defining cloud regimes.

The relationships CDNC|AOD and CF|CDNC produce Figure 6 when combined. This shows the probability of a given $C F$ being retrieved, given that a certain $A O D$ has been retrieved and assuming that CF changes are mediated by CDNC changes. This is referred to as the AOD-CDNC-CF relationship (in contrast to the AOD-CF 

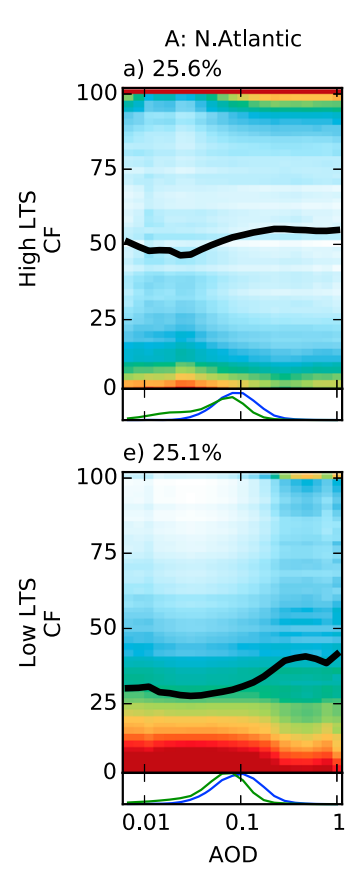

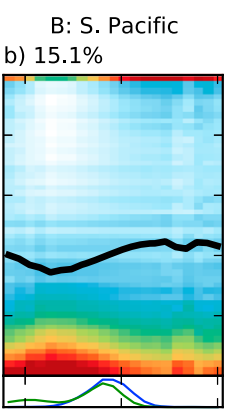

f) $32.2 \%$

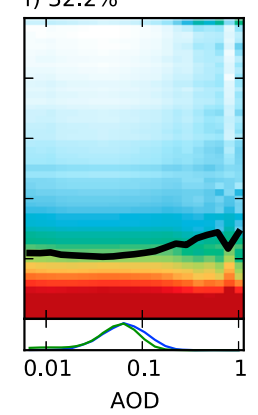

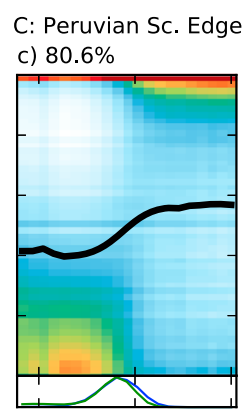

g) $2.7 \%$

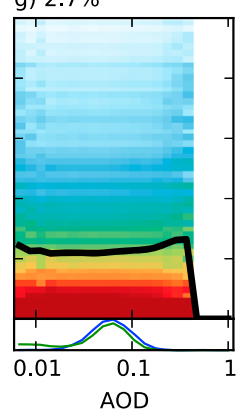

D: Namibian Sc. d) $69.1 \%$

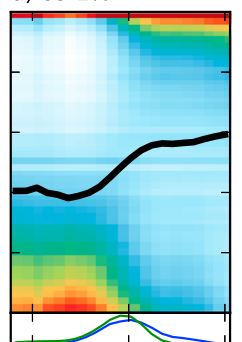

h) $2.5 \%$

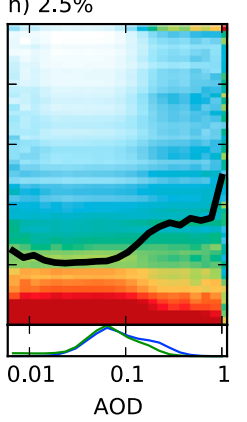

|

Figure 6. The liquid CF probability distribution given a certain AOD observation and assuming the relationship is mediated by CDNC $\left(f_{c} \mid \mathrm{do}\left(\tau_{a}\right)\right)$. This plot is generated by combining Figures 4 and 5 and normalized (although not explicitly) so that the columns sum to $100 \%$.

relationship in Figure 3) or CF|doAOD, given its connection to the "do" probabilities in the previous section. Again, there is a difference between the different LTS regimes, and between the tropical and the extratropical locations.

In the high LTS regime, there is an increase in CF with increasing CDNC, with the increase occurring primarily between 0.05 and 0.2 AOD. At lower and higher AODs, there is a much weaker relationship between AOD and CF. This "step" is much clearer in the tropical stratocumulus regions (C and D). In the extratropical regions, there is a much smaller increase in CF with increasing AOD, and less obvious switch between low CF and high CF states. If this change in CF is due to an effect of aerosols, the switch between low and high CF states would suggests that an aerosol influence on CF could saturate at high aerosol levels. The AOD distributions in Figure $6 \mathrm{~d}$ suggest that this saturation may already be occurring in heavily polluted regions, as the majority of retrieved AODs in the Namibian Stratocumulus region are above the "step". The low LTS regime shows only a weak relationship between $A O D$ and $C F$. Although the cleaner regions $(B, C)$ show almost no relationship between $A O D$ and $C F$, the more polluted regions $(A, D)$ show an increase in CF with increasing AOD for AODs larger than about 0.1. This is due to the increase in CDNC with AOD for AODs around 0.1, coupled with the increase in CF with CDNC seen in this region. This is partly due to the reduced utility of LTS as a regime separator in the extratropics, but it is possible that varying aerosol types could also play a role.

\subsection{Global Results}

The large difference in the AOD-CDNC-CF relationship between the regimes suggests that the frequency of occurrence of these regimes may influence the global pattern of the AOD-CDNC-CF relationship. To reduce the number of convolved relationships, the linear regression between $\ln (A O D)$ and $C F$ is used, determined from the AOD-CF and AOD-CDNC-CF joint histograms (see Figures 3 and 6). By considering the histogram as a cloud of points, each weighted by its frequency of occurrence, the necessary statistics for a linear regression can be calculated. This has the effect of weighting the histograms by the AOD distribution, meaning that the linear regression approximates one calculated from the individual datapoints that make up the histogram. Using linear regressions removes the influence of the size of the local AOD variance, so that the strength of the relationships is determined primarily by the sensitivity of CF to AOD (influenced by cloud type/regime) and the aerosol type.

As seen in Figure 7a, a higher liquid CF in ice cloud-free regions is found in regions of a higher AOD, generating a positive regression slope between them. The AOD-CF relationship shows a similar spatial pattern to that 
a)

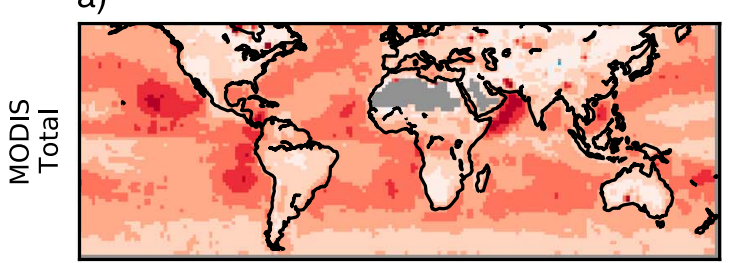

c)

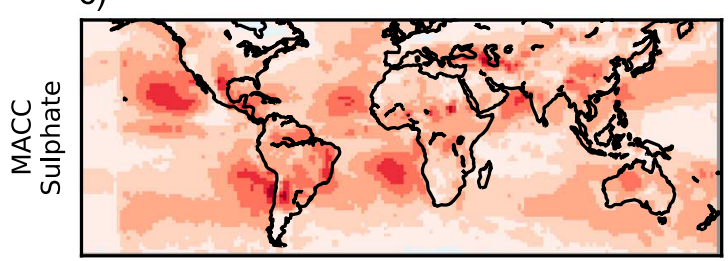

e)

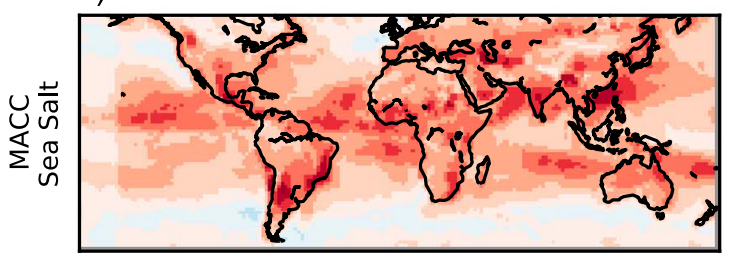

g)
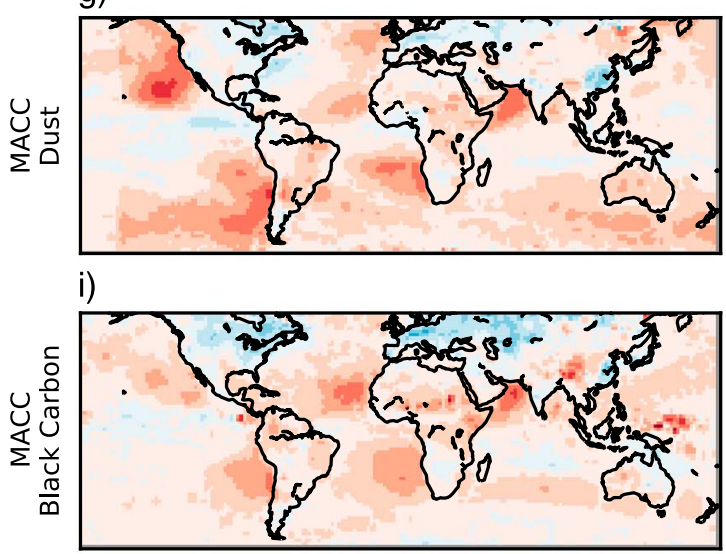

k)
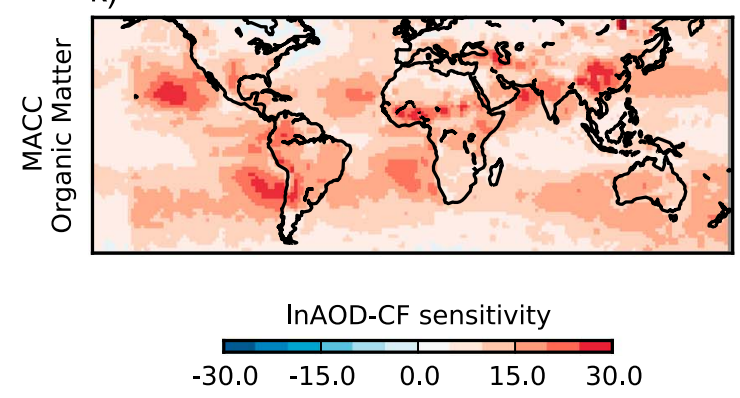

b)

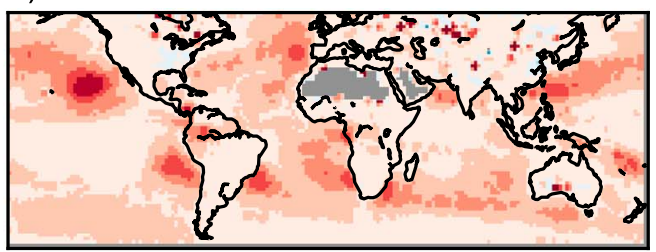

d)

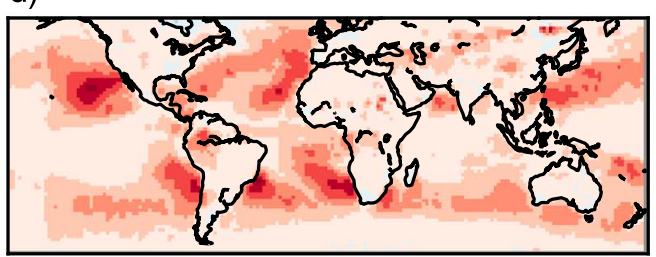

f)

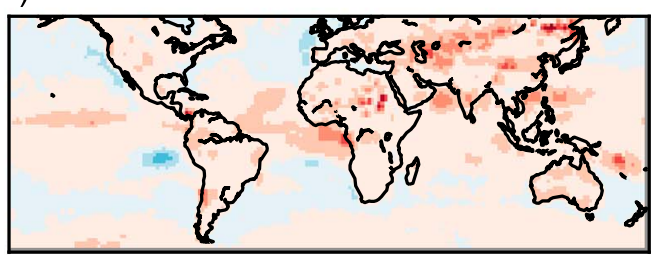

h)
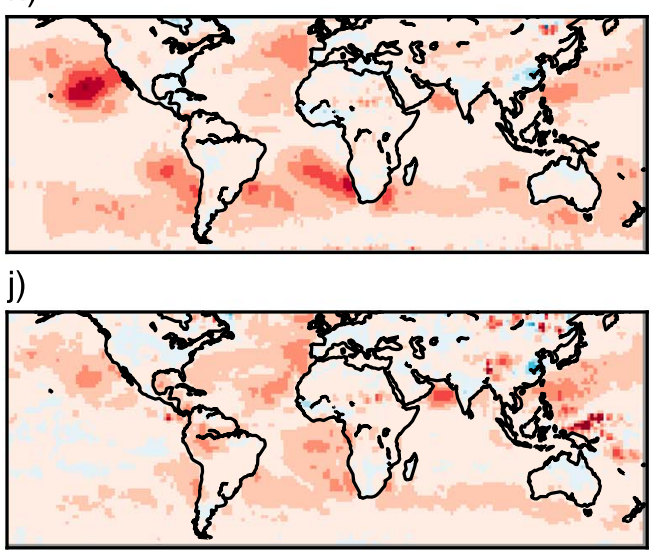

I)
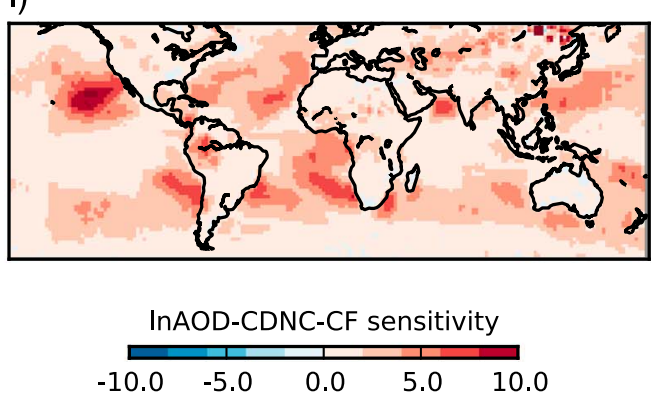

Figure 7. Linear regressions of ice-free liquid CF against $\log (A O D)$. (a, c, e, g, i, and k) The slope of the regression of liquid $C F$ against $\ln (A O D)$. (b, $d, f, h, j$, and $I$ ) The same but requiring the relationship to be mediated by CDNC. The first row $(a, b)$ uses MODIS AOD as the AOD product, with the remaining rows using speciated AOD from the MACC reanalysis. These regressions are determined from joint histograms such as those in Figures 3 and 6 . The slope is an average of the slopes determined for each month. Grey regions indicate missing data. Note the different scales for the columns. The reduced sensitivity near the dateline is due to the difficulty in determining the MODIS overpass time in this region. The differences between the methods are shown in the supporting information. 
Table 1. Global Mean Regression Slopes for Figure 7 and the Percentage Change Between the InAOD-CF and InAOD-CDNC-CF Relationships

\begin{tabular}{lccc} 
& InAOD-CF & $\begin{array}{c}\text { Change } \\
\text { CDNC-CF }\end{array}$ & -84 \\
\hline MODIS total & 10.5 & 1.7 & -76 \\
MACC sulphate & 7.8 & 1.8 & -94 \\
MACC sea salt & 8.5 & 0.5 & -60 \\
MACC dust & 3.1 & 1.2 & -48 \\
MACC black carbon & 1.7 & 0.9 & -75 \\
MACC organic matter & 6.8 & 1.7 & \\
\hline
\end{tabular}

seen in previous work looking at the total CF [Kaufman et al., 2003; Grandey et al., 2014; Gryspeerdt et al., 2014a], although the magnitude is smaller. This reduction in magnitude is possibly due to a reduction in cirrus contamination of the AOD retrieval [Huang et al., 2011], as this study is restricted to $1^{\circ}$ by $1^{\circ}$ grid boxes where no ice cloud has been detected. Although the AOD-CF relationship is of a similar magnitude over most of the globe, there is a stronger relationship observed in the stratocumulus regions. There is also a stronger relationship in the Arabian sea, possibly due to retrieval errors in this region [Hubanks et al., 2008]. The AOD-CF relationship is weaker in the Southern Ocean, and there is also a weak positive relationship over many land regions. Due to the strength of meteorological covariations and retrieval errors on the AOD-CF relationship, much of the relationship in Figure 7a is thought to be due to factors other than the influence of aerosols on CF.

Requiring a mediating influence from the CDNC weakens the AOD-CF relationship considerably (Figure 7b, note the change of scale), although a positive relationship is found almost everywhere. This AOD-CDNC-CF relationship displays a number of different features compared to the AOD-CF relationship. There is a significant reduction in the strength of the relationship in shallow cumulus regions (such as the central Pacific), while the stratocumulus regions show a comparatively strong AOD-CDNC-CF relationship. Outflows from China and South America, along with the "river of smoke" from southern Africa [Swap, 2003], are all visible with relatively strongly positive regressions. There is also a strong AOD-CDNC-CF relationship in the north Atlantic, close to Europe. Over land, the AOD-CF relationship is significantly reduced by requiring CDNC mediation, in many cases disappearing altogether. This is related to the low CDNC sensitivity to AOD over land that has also been observed in previous work [Quaas et al., 2008].

\subsection{Dependence on Aerosol Species}

As different aerosol types have different properties when acting as CCN, the MACC reanalysis dataset is also used to provide information on the aerosol species present. Each of the plots in Figures $7 c-71$ make use of the MACC speciated AOD, instead of the MODIS total AOD. This reduces the influence of regional aerosol-type variations on the global MODIS AOD-CF sensitivity plots (Figures 7a and 7b), although it is not possible to completely remove the impact of variations in aerosol properties, as some aerosol types may covary. As with the MODIS results, each of these plots shows the slope of a linear regression determined from the joint histogram of $A O D$ and $C F$, weighted by the frequency of occurrence of each AOD bin.

The AOD-CF relationship for each of the aerosol types is mostly positive. The hydrophilic types (sulphate, sea salt, and organic matter) show higher sensitivities of CF to AOD variations than the more hydrophobic types (dust and black carbon), which even show a negative AOD-CF relationship in some regions. There is some evidence of a regional pattern, with a stronger AOD-CF relationship in the stratocumulus regions for sulphate and organic matter.

When requiring CDNC to mediate the AOD-CF relationship, there is a significant drop in the strength of the AOD-CF relationship (Table 1 -regional values are given in the supporting information (SI)). This AOD-CDNC-CF relationship is shown for the varying aerosol types in Figures $7 \mathrm{~b}, 7 \mathrm{~d}, 7 \mathrm{f}, 7 \mathrm{~h}, 7 \mathrm{j}$, and $7 \mathrm{l}$. As expected, sulphate and organic matter show a relatively strong AOD-CDNC-CF relationship, due to their properties as CCN [Andreae and Rosenfeld, 2008]. Although the north Pacific stratocumulus region shows a much stronger sensitivity than the Southern Hemisphere stratocumulus regions, when the aerosol type is limited to sulphate aerosol, the hemispheric asymmetry sensitivity in the stratocumulus regions is reduced (Figure 7d), highlighting the importance of the aerosol type in determining the AOD-CDNC-CF sensitivity. With its largely hydrophobic properties, uncoated black carbon is thought to be a poor CCN. This would agree with the weak 
AOD-CDNC-CF relationship shown here, much of which may be attributable to the covariation of black carbon with other species that are active as CCN. The strong organic matter AOD-CDNC-CF relationship also indicates that the strong AOD-CDNC-CF relationship off the east coasts of South America and South Africa is due to the large amount of organic aerosols in these regions. The global mean sensitivity provides a coarse indicator of the strength of the AOD-CF and AOD-CDNC-CF relationships. The percentage reduction in the strength of the AOD-CDNC-CF relationship when compared to the AOD-CF relationship is larger for the hydrophilic aerosol types (Table 1, right hand column). This suggests that the confounding effect being removed by the CDNC mediation affects hydrophilic aerosol types more strongly (as for these types the AOD-CF relationship is a larger overestimation when compared to the AOD-CDNC-CF relationship). This adds further support to the theory that the CDNC mediation is accounting for aerosol hygroscopic growth and that this is a primary contributor to the AOD-CF relationship [Quaas et al., 2010].

The AOD-CDNC-CF relationship when using sea salt AOD is much smaller than the AOD-CF relationship, becoming negative in the stratocumulus regions. This is due to a decrease in retrieved CDNC at high sea salt $A O D$ in these regions, although there is a positive AOD-CDNC relationship at low sea salt AOD. It is possible that this reduction in CDNC and so CF could be due to the increased influence of coarse CCN at high AOD. Previous observations have suggested that increases in coarse CCN are correlated with increases in cloud drop effective radius [Lehahn et al., 2011], which would be consistent with a reduction in CDNC. However, it is also possible that some other factor, such as a wind-driven meteorological covariation [e.g., Engstrom and Ekman, 2010], is generating this reduction in CF with increasing AOD.

As a normally hydrophobic aerosol type, the strong AOD-CDNC-CF relationship for dust is interesting. The AOD-CDNC-CF relationship for dust (Figure $7 \mathrm{~h}$ ) is almost as strong as that for sulphate (Figure 7d) or organic matter (Figure 7l) in several regions, such as the edges of the Californian and Namibian stratocumulus decks. However, the dust AOD-CDNC-CF relationship is much weaker in regions where dust is dominant, such as the tropical Atlantic ocean and the Arabian ocean.

There are several possible reasons for the strength of the dust AOD-CDNC-CF relationship. It is unlikely that weak AOD-CDNC-CF relationship in the dust dominated regions is due to the cloud types in these regions being insensitive to aerosol types. For example, although the tropical Atlantic shows a weak dust AOD-CDNC-CF relationship, there is a strong sulphate AOD-CDNC-CF relationship, suggesting that changes in cloud properties are not responsible for the weak dust AOD-CDNC-CF relationship in this region. It is possible that the properties of the dust aerosol change as it moves further from source regions, acquiring a coating that makes it a better CCN [e.g., Rosenfeld et al., 2001, 2010]. It is also possible that the dust in these regions covaries with more hydrophilic aerosol in these regions. Unfortunately, it is not currently possible to distinguish a change in aerosol properties from an error in the MACC aerosol speciation, especially far from sources. However, as the dust AOD is small in the regions with a strong dust AOD-CDNC-CF relationship, it does not have large consequences for the results presented here.

\subsection{Implied Radiative Forcing}

Although there may still be meteorological covariations and retrieval errors in the AOD-CDNC-CF relationship, it is useful to consider the implied radiative forcing to evaluate the plausibility of these results and to provide a constraint on the strength of possible aerosol-cloud interactions. Current estimates suggest a total aerosol indirect forcing of between 0 and $-1.2 \mathrm{~W} \mathrm{~m}^{-2}$ [Boucher et al., 2013], so an apparent radiative effect much larger than this might indicate the influence of meteorological covariation or retrieval errors. This is not a conclusive test, as there may be large positive forcings resulting from aerosol effects that could cancel out a large negative forcing from aerosol-cloud interactions [e.g., Koren et al., 2010b]. As noted in Quaas et al. [2008], considering the pure sensitivity of CF to AOD (such as that shown in Figure 7a) implies a globally averaged forcing of over $-3 \mathrm{~W} \mathrm{~m}^{-2}$, which is large compared to the current anthropogenic $\mathrm{CO}_{2}$ radiative forcing of $1.6 \mathrm{~W} \mathrm{~m}^{-2}$ and significantly larger than model-based estimates of the aerosol influence on CF [Quaas et al., 2009].

To calculate the implied TOA SW forcing, the change in ice-free liquid CF is calculated using both the full $\mathrm{CF} \mid$ doAOD histogram (Figure 6) and the linear regression from the histogram. For locations in the histogram with no data available at AODs corresponding to the natural AOD level, data are interpolated from the nearest available AOD bin. This method relies on the accuracy of AOD retrievals at low AOD and on the applicability of the interpolation method. As these interpolated results may not adequately represent the cloud properties at low aerosol levels [Penner et al., 2011], the implied forcing is also calculated from a linear regression applied to the $P(C F \mid$ doAOD) histogram (as in Figure 7). Although a linear regression cannot account for nonlinearities, 
a)

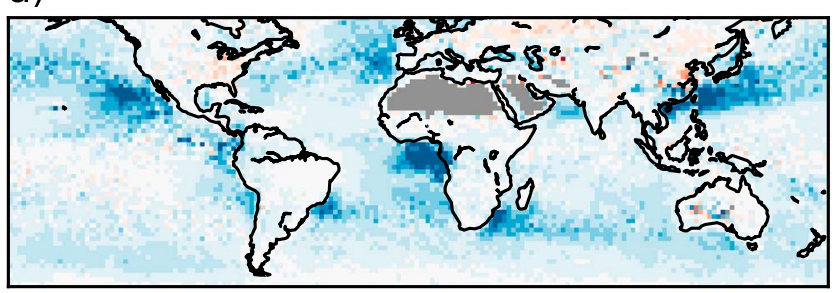

b)

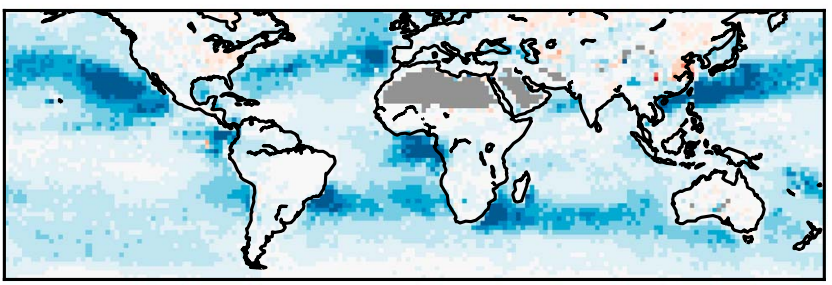

c)
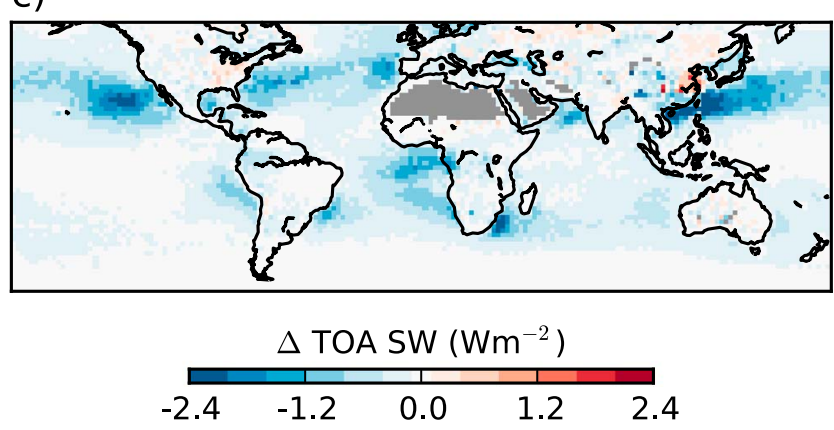

Figure 8. The difference in CERES TOA SW radiation implied by the AOD-CDNC-CF relationship between preindustrial and present day. (a) The radiation change implied by a change in CF using the full joint probability histograms. (b) The same, but using a linear regression from each joint histogram, weighted by the present-day AOD distribution. Natural AOD is determined using the MACC anthropogenic AOD fraction of Bellouin et al. [2013]. (c) The same as Figure 8b, but using an anthropogenic aerosol fraction from MACv2 (updated from Kinne et al. [2013]). The linear regression between the CF and the all-sky SW TOA flux is used to provide a link between CF and TOA SW radiation. The MODIS liquid cloud fraction is used to relate liquid and total CF. The CERES data used are SSF data at $1^{\circ}$ by $1^{\circ}$ resolution over the period 2003-2013 inclusive.

it is less reliant on the AOD retrievals at low AOD, making it a more suitable central estimate. Regions with missing data are assumed to have no aerosol influence on $C F$, an appropriate assumption in many cases as these regions often lack liquid water clouds (e.g., Sahara desert). These calculations are performed for each season and grid boxes with more than 25 datapoints are combined to create an annual estimate of the implied forcing.

The approximate radiative effect calculated from the full histograms is shown in (Figure 8a). Although it can reach over $-2 \mathrm{~W} \mathrm{~m}^{-2}$ regionally, the mean across the region $60^{\circ} \mathrm{N}$ to $60^{\circ} \mathrm{S}$ is approximately $-0.37 \mathrm{~W} \mathrm{~m}^{-2}$ resulting from a mean increase in liquid CF of $0.67 \%$ (absolute percent). The implied forcing from the linear regression of the AOD-CDNC-CF relationship is $-0.48 \mathrm{~W} \mathrm{~m}^{-2}$ (Figure $8 \mathrm{~b}$ ) and significantly less noisy. A significant part of the implied forcing comes from the Southern Hemisphere. Ignoring the forcing south of $15^{\circ} \mathrm{S}$ gives a total forcing of $-0.30 \mathrm{~W} \mathrm{~m}^{-2}$, of which $-0.25 \mathrm{~W} \mathrm{~m}^{-2}$ comes from the Northern Hemisphere alone. The pattern of forcing in the Northern Hemisphere is similar to that found in some global climate models [Zelinka et al., 2014]. The statistical uncertainty on this forcing estimate is small, with a bootstrapped error estimate giving an uncertainty of $0.05 \mathrm{~W} \mathrm{~m}^{-2}$. However, the uncertainty in the preindustrial state of the atmosphere generates a significantly larger uncertainty in the implied forcing. Repeating the implied forcing calculation with a $50 \%$ increase and decrease in the anthropogenic AOD fraction from MACC gives an uncertainty range of -0.19 to $-0.64 \mathrm{~W} \mathrm{~m}^{-2}$. Using the MACv2 anthropogenic fraction and the linear regression of the AOD-CDNC-CF relationship gives an implied forcing of $-0.25 \mathrm{~W} \mathrm{~m}^{-2}$ (Figure $8 \mathrm{c}$ ), further demonstrating the uncertainty that results from our poor knowledge of the preindustrial aerosol concentration. 
Previous estimates of the aerosol influence on cloud albedo or the first indirect effect [Quaas et al., 2008, $-0.2 \pm 0.1 \mathrm{~W} \mathrm{~m}^{-2}$; Lebsock et al., 2008, $-0.42 \mathrm{~W} \mathrm{~m}^{-2}$ ] also depend on the strength of the AOD-CDNC relationship and so would likely vary in strength together with the AOD-CDNC-CF relationship, rather than in opposition. Combining the high and low estimates of the two effects gives an effective radiative forcing from aerosol-cloud interactions of between -0.29 and $-1.06 \mathrm{~W} \mathrm{~m}^{-2}$, although this estimate does not include interactions with radiation, possible effects on cloud liquid water path, effects on ice- or mixed phase clouds, or effects in the terrestrial spectrum. This estimate is consistent with the Intergovernmental Panel on Climate Change (IPCC) best estimate of $-0.45 \mathrm{~W} \mathrm{~m}^{-2}\left(0.0\right.$ to $\left.-1.2 \mathrm{~W} \mathrm{~m}^{-2}\right)$ for the effective radiative forcing from aerosol-cloud interactions. Some studies point to the IPCC estimate as being weaker than observational constraints suggest [Quaas et al., 2009; Cherian et al., 2014], although a recent study has suggested that the upper end of this uncertainty range is not consistent with historical temperature trends [Stevens, 2015], which in turn would suggest the upper end of the uncertainty range in this work is less likely.

\section{Discussion}

Although this method produces an observational estimate for the influence of aerosol on CF with a reduced impact of meteorological covariations, some caveats remain, with a corresponding uncertainty in the strength of the aerosol influence on CF. In addition to uncertainty in the anthropogenic aerosol fraction, uncertainties remain in the AOD-CDNC-CF relationship. The main possible sources of uncertainty are as follows.

1. The satellite-retrieved CDNC is an important part of this work, but assuming adiabatic clouds when calculating it can result in errors [Merk et al., 2015]. However, this work does not depend on the exact relationship between the "real" CDNC and the retrieved CDNC, as long as there is a strictly monotonic relationship between the retrieved and the "real" CDNC (the results in this work do not require knowledge exact value of $\gamma$, or for it to be constant). As the relationship between AOD and "real" CDNC is likely strictly monotonic, the monotonic relationship between AOD and retrieved CDNC observed in this work suggests that the relationship between the "real" CDNC and the retrieved CDNC is also monotonic. When using effective radius as the mediating variable, a similar implied forcing is obtained $\left(-0.26 \mathrm{~W} \mathrm{~m}^{-2}\right)$, although it is smaller as the effective radius is further from the causal pathway than CDNC [McComiskey and Feingold, 2012]. This indicates that relying on the adiabatic assumption does not result large biases in this work.

2. The filtering of the data for liquid clouds with valid CDNC retrievals may also generate uncertainties. Selecting only grid boxes that are free of ice cloud may influence the results in this work. However, the impact of this is likely to be small, as liquid clouds could be expected to behave in a similar manner irrespective of whether there is an ice cloud in the same grid box (unless they are overlapping). A larger possible uncertainty comes from the exclusion of pixels with no valid CDNC retrieval, removing around $25 \%$ of possible pixels. Fewer pixels are excluded over ocean (around 17\%), mainly from regions where shallow cumulus clouds are more common. One possible solution is to assign zero CF pixels a CDNC of zero, implicitly assuming that all zero CF cases are CCN limited. This gives an almost 200\% increase in the implied forcing, but as only about $5 \%$ of oceanic pixels have an AOD retrieval below 0.02 (indicating a possible CCN limited case), neglecting zero CF cases is unlikely to result in more than a $10 \%$ underestimation in the implied forcing. Additionally, assigning zero CDNC to clear-sky pixels allows information to bypass the CDNC mediation, increasing the role of the confounding factors and suggesting that the underestimation due to excluding clear-sky pixels is likely to be even smaller. Investigating the impact of the sampling biases would require a global model and satellite simulator, providing an interesting avenue for future research.

3. Biases in the CDNC retrieval as a function of CF may also influence the AOD-CDNC-CF relationship. In broken cloud regimes, cloud inhomogeneity can result in an overestimation of the $2.1 \mu \mathrm{m}$ effective radius, leading to an underestimation of the CDNC [Zhang and Platnick, 2011]. Although this may generate a relationship between CDNC and CF, other studies have found an increase in CDNC with increasing inhomogeneity [Grosvenor and Wood, 2014], making it unclear how exactly cloud inhomogeneity would impact the CDNC-CF relationship. If the CDNC is underestimated by $50 \%$ in low CF locations but accurate at $100 \%$ CF, this would result in a reduction of the implied forcing by around $50 \%$ (see $\mathrm{SI}$ ). To include this possibility, the upper bound on the uncertainty in implied radiative forcing is moved from -0.19 to $-0.1 \mathrm{~W} \mathrm{~m}^{-2}$. However, investigations with carefully chosen CDNC retrievals indicate that the error in the CDNC-CF relationship due to CF heterogeneity effects is almost certainly less than this (see $\mathrm{SI}$ ).

4. This method excludes any effect that does not impact the CDNC. This accounts for the main known confounding variable $(\mathrm{RH})$, but it is still possible that other confounding factors exist. These factors do not have 
to be explicitly accounted for as long as they do not influence the CDNC (i.e., CDNC is independent from $M$ in Figure $1 \mathrm{~b}$ ). For example, although wind speed is correlated to both $\mathrm{AOD}$ and $\mathrm{CF}$, generating a correlation between them [Engstrom and Ekman, 2010; Brueck et al., 2015], it is not strongly correlated to CDNC and so is not responsible for the results in this work. The same is true of convergence and cloud effects on aerosol properties, which although they may be responsible for a large part of the AOD-CF relationship [Jeong and $L i, 2010]$, do not impact CDNC directly. However, the existence of LTS regimes shows that CDNC is influenced by some of the same meteorological properties as AOD and CF. This could result in an overestimate of the AOD-CDNC-CF relationship in regions where the LTS regimes commonly mix, although the regional results show that the AOD-CDNC-CF relationship remains positive even when considering the LTS regimes separately. Other meteorological covariations cannot be ruled out, even if the influence of meteorology, and hygroscopic growth in particular, has been greatly reduced. Additionally, this method excludes aerosol interactions with cloud properties do not modify the CDNC, such as the semidirect effect. This is an important area for future investigation, particularly into the form of the relationship in Figure $1 \mathrm{~b}$, to determine if extra mediating variables can incorporate the effect of other aerosol-cloud interactions and remove the impact of any remaining confounding factors.

\section{Conclusions}

This work has demonstrated how a method for determining causality in complex systems can reduce the impact of meteorological covariations on the AOD-CF relationship. It has a number of advantages when investigating aerosol cloud interactions, due to the complex nature of the relationships involved and the difficulty in explicitly accounting for every possible meteorological covariation.

The method is based on the work of Pearl [1994], which suggests that if two variables (AOD and CF) are correlated, but also influenced by a third (unknown or unmeasurable) factor (e.g., meteorological covariations, retrieval errors), it is impossible to determine the causal relationship between these two variables unless the controlling factor can be measured and accounted for. Although theoretical and experimentally based models exist for the controlling factors when considering the AOD-CF relationship (such as aerosol hygroscopic growth), it has proven difficult to explicitly account for these variables. However, if another variable along the causal pathway from AOD to CF (CDNC in this case) is used, the effect of the unknown or unmeasurable meteorological covariations can be accounted for, provided that the new variable is independent of these meteorological covariations. This method uses joint histograms to examine the relationship between $A O D, C D N C$, and CF, accounting for variations in relative humidity. The use of joint histograms, rather than a simple linear regression preserves the nonlinearity in these relationships, allowing the nonlinearity in the AOD-CDNC-CF relationship to be considered.

The global pattern of the AOD-CDNC-CF relationship is strongly related to the cloud properties. Strong AOD-CDNC-CF relationships are found along the edge of stratocumulus zones, in high LTS regions. This may indicate a role of aerosols in transitions between closed and open-celled stratocumulus, increasing CF in stratocumulus regions with increasing $A O D$. In these regions, $C F$ is relatively insensitive to $A O D$ variations at low and high AOD. However, when the AOD is around 0.1, there is a strong relationship between AOD and CF, switching the CF from the low CF state found at low AOD to a higher CF state found at high AOD. This is in part due to a strong response of CF to CDNC changes in the high LTS regime. Shallow cumulus clouds found at low LTS have a very weak relationship between AOD and CF, which is due to an apparent inability of CDNC to influence CF in this regime (similar to model-based results [Seifert et al., 2015]).

By requiring a mediating effect of $C D N C$, this method significantly reduces the strength of the AOD-CF relationship. When compared to the AOD-CF relationship, a linear regression of the AOD-CDNC-CF relationship suggests that the relationship is around $20 \%$ of that determined from the AOD-CF relationship, with the change in CF between present day and natural aerosol levels implying a TOA SW forcing of $-0.48 \mathrm{~W} \mathrm{~m}^{-2}$.

Several uncertainties remain in this estimate of the implied radiative forcing, although it provides a useful plausibility check on the results. The large uncertainty range on the anthropogenic aerosol fraction makes the largest contribution to the total uncertainty. It is also possible that CDNC retrieval errors are a function of CF, leading to an overestimate of the strength of the AOD-CDNC-CF relationship. When these sources of uncertainty are combined with the statistical uncertainty in the AOD-CDNC-CF relationship, this leads to an uncertainty range of -0.1 to $-0.64 \mathrm{~W} \mathrm{~m}^{-2}$. 
Acknowledgments

The MODIS data are from the NASA Goddard Space Flight Center (ftp://laadsweb.nascom.nasa.gov). The CERES data were obtained from the Atmospheric Sciences Data Center at NASA Langley Research Center (http://ceres.larc.nasa.gov). The MACC reanalysis data are available on-line at http://apps.ecmwf.int/datasets/data/ macc-reanalysis/. This work received funding from the European Research Council under the European Union's Seventh Framework Programme (FP7/2007-2013) / ERC grant agreement FP7-306284 (QUAERERE) and grant agreement 218793 (MACC-II) as well as Horizon2020 grant agreement 633080 (MACC-III). The authors would like to thank Bjorn Stevens (Max Planck Institute for Meteorology) as well as two anonymous reviews, whose comments have helped to improve this work.
By design, this method excludes any possible aerosol effects on CF that do not modify the CDNC (such as the semidirect effect) and it is also unable to remove the influence of confounding factors that impact CDNC along with AOD and CF. It is clear that LTS still exerts an influence on the AOD-CDNC-CF relationship and further unknown confounding factors may still bias the AOD-CDNC-CF relationship and the implied radiative forcing in this work. Although the influence of these unknown factors in not clear, the method in this work has reduced the impact of the largest known confounding factor (relative humidity), along with other factors that are unable to modify the CDNC (such as wind speed).

To further constrain of the estimated aerosol impact on $C F$, future investigation into the components of the AOD-CDNC-CF relationship is required, particularly into the CDNC-CF relationship and how the CDNC affects the transition between open and closed celled stratocumulus. The suitability of using the AOD-CDNC-CF relationship shown in Figure $1 \mathrm{~b}$ should also be investigated, especially how it is influenced by confounding factors, and which further mediating variables could be used to account for such factors.

This work has demonstrated the potential of using joint histograms and intermediate variables when investigating aerosol-cloud interactions using satellite data. By using extra information about cloud properties, the impact of meteorological covariations, particularly those due to aerosol humidification have been reduced. In doing so, an improved observational estimate of the possible aerosol influence on CF has been determined that is in better agreement with estimates from models and inverse studies.

\section{References}

Ackerman, S., O. Toon, D. Stevens, A. Heymsfield, V. Ramanathan, and E. Welton (2000), Reduction of tropical cloudiness by soot, Science, 288, 1042-1047, doi:10.1126/science.288.5468.1042.

Albrecht, B. (1989), Aerosols, cloud microphysics, and fractional cloudiness, Science, 245, 1227-1230, doi:10.1126/science.245.4923.1227.

Andreae, M. (2009), Correlation between cloud condensation nuclei concentration and aerosol optical thickness in remote and polluted regions, Atmos. Chem. Phys., 9, 543-556, doi:10.5194/acp-9-543-2009.

Andreae, M., and D. Rosenfeld (2008), Aerosol cloud precipitation interactions. Part 1. The nature and sources of cloud-active aerosols, Earth Sci. Rev., 89, 13-41, doi:10.1016/j.earscirev.2008.03.001.

Bellouin, N., G. W. Mann, M. T. Woodhouse, C. Johnson, K. S. Carslaw, and M. Dalvi (2013), Impact of the modal aerosol scheme GLOMAP-mode on aerosol forcing in the Hadley Centre Global Environmental Model, Atmos. Chem. Phys., 13, 3027-3044, doi:10.5194/acp-13-3027-2013.

Bender, F. A.-M., R. J. Charlson, A. M. L. Ekman, and L. V. Leahy (2011), Quantification of monthly mean regional-scale albedo of marine stratiform clouds in satellite observations and GCMs, J. App. Met. Clim., 50(10), 2139-2148, doi:10.1175/JAMC-D-11-049.1.

Bennartz, R. (2007), Global assessment of marine boundary layer cloud droplet number concentration from satellite, J. Geophys. Res., 112, D02201, doi:10.1029/2007JD007547.

Boucher, O., and J. Quaas (2012), Water vapour affects both rain and aerosol optical depth, Nat. Geosci., 6, 4-5, doi:10.1038/ngeo1692.

Boucher, O., et al. (2013), Clouds and Aerosols, Book Section 7, pp. 571-658, Cambridge Univ. Press, Cambridge, U. K., and New York, doi:10.1017/CBO9781107415324.016.

Brenguier, J.-L., H. Pawlowska, L. Schüller, R. Preusker, J. Fischer, and Y. Fouquart (2000), Radiative properties of boundary layer clouds: Droplet effective radius versus number concentration, J. Atmos. Sci., 57, 803-821,

doi:10.1175/1520-0469(2000)057<0803:RPOBLC>2.0.CO;2.

Brennan, J., Y. Kaufman, I. Koren, and R. Li (2005), Aerosol cloud interaction-misclassification of MODIS clouds in heavy aerosol, IEEE T. GeoSci. Remote, 43, 911-915, doi:10.1109/TGRS.2005.844662.

Brueck, M., L. Nuijens, and B. Stevens (2015), On the seasonal and synoptic time-scale variability of the North Atlantic trade wind region and its low-level clouds, J. Atmos. Sci., 72(4), 1428-1446, doi:10.1175/JAS-D-14-0054.1.

Cherian, R., J. Quaas, M. Salzmann, and M. Wild (2014), Pollution trends over Europe constrain global aerosol forcing as simulated by climate models, Geophys. Res. Lett., 41, 2176-2181, doi:10.1002/2013GL058715.

Costantino, L., and F.-M. Bréon (2010), Analysis of aerosol-cloud interaction from multi-sensor satellite observations, Geophys. Res. Lett., 37, L11801, doi:10.1029/2009GL041828.

Costantino, L., and F.-M. Bréon (2013), Aerosol indirect effect on warm clouds over South-East Atlantic, from co-located MODIS and CALIPSO observations, Atmos. Chem. Phys., 13, 69-88, doi:10.5194/acp-13-69-2013.

Dee, D. P., et al. (2011), The ERA-Interim reanalysis: Configuration and performance of the data assimilation system, Q. J. R. Meteorol. Soc., 137(656), 553-597, doi:10.1002/qj.828.

Dey, S., G. L. Di, G. Zhao, A. L. Jones, and G. M. McFarquhar (2011), Satellite-observed relationships between aerosol and trade-wind cumulus cloud properties over the Indian Ocean, Geophys. Res. Lett., 38, L01804, doi:10.1029/2010GL045588.

Engstrom, A., and A. M. Ekman (2010), Impact of meteorological factors on the correlation between aerosol optical depth and cloud fraction, Geophys. Res. Lett., 37, L18814, doi:10.1029/2010GL044361.

Grandey, B., and P. Stier (2010), A critical look at spatial scale choices in satellite-based aerosol indirect effect studies, Atmos. Chem. Phys., 10, 11,459-11,470, doi:10.5194/acp-10-11459-2010.

Grandey, B. S., P. Stier, and T. M. Wagner (2013), Investigating relationships between aerosol optical depth and cloud fraction using satellite, aerosol reanalysis and general circulation model data, Atmos. Chem. Phys., 13, 3177-3184, doi:10.5194/acp-13-3177-2013.

Grandey, B. S., A. Gururaj, P. Stier, and T. M. Wagner (2014), Rainfall-aerosol relationships explained by wet scavenging and humidity, Geophys. Res. Lett., 41, 5678-5684, doi:10.1002/2014GL060958.

Granger, C. W. J. (1969), Investigating causal relations by econometric models and cross-spectral methods, Econometrica, 37, 424-438, doi:10.2307/1912791.

Grosvenor, D. P., and R. Wood (2014), The effect of solar zenith angle on MODIS cloud optical and microphysical retrievals within marine liquid water clouds, Atmos. Chem. and Phys., 14(14), 7291-7321, doi:10.5194/acp-14-7291-2014. 
Gryspeerdt, E., and P. Stier (2012), Regime-based analysis of aerosol-cloud interactions, Geophys. Rev. Lett., 39, L21802, doi:10.1029/2012GL053221.

Gryspeerdt, E., P. Stier, and B. Grandey (2014a), Cloud fraction mediates the aerosol optical depth-cloud top height relationship, Geophys. Rev. Lett., 41, doi:10.1002/2014GL059524.

Gryspeerdt, E., P. Stier, and D. G. Partridge (2014b), Satellite observations of cloud regime development: The role of aerosol processes, Atmos. Chem. Phys., 14, $1141-1158$, doi:10.5194/acp-14-1141-2014.

Gryspeerdt, E., P. Stier, B. A. White, and Z. Kipling (2015), Wet scavenging limits the detection of aerosol effects on precipitation, Atmos. Chem. Phys., 15(13), 7557-7570, doi:10.5194/acp-15-7557-2015.

Haywood, M. J., R. S. Osborne, and J. S. Abel (2004), The effect of overlying absorbing aerosol layers on remote sensing retrievals of cloud effective radius and cloud optical depth, Q. J. R. Meteorol. Soc., 130, 779-800, doi:10.1256/qj.03.100.

Huang, J., N. Hsu, S.-C. Tsay, M.-J. Jeong, B. Holben, T. Berkoff, and E. Welton (2011), Susceptibility of aerosol optical thickness retrievals to thin cirrus contamination during the BASE-ASIA campaign, J. Geophys. Res., 116, D08214, doi:10.1029/2010JD014910.

Hubanks, P. A., M. D. King, S. A. Platnick, and R. A. Pincus (2008), MODIS atmosphere L3 gridded product algorithm theoretical basis document no. atbd-mod-30, Tech. Rep., National Aeronautics and Space Administration.

Jeong, M.-J., and Z. Li (2010), Separating real and apparent effects of cloud, humidity, and dynamics on aerosol optical thickness near cloud edges, J. Geophys. Res., 115, D00K32, doi:10.1029/2009JD013547.

Kaufman, Y., J. Haywood, P. Hobbs, W. Hart, R. Kleidman, and B. Schmid (2003), Remote sensing of vertical distributions of smoke aerosol off the coast of Africa, Geophys. Res. Lett., 30(16), 1831.

Kaufman, Y., I. Koren, L. Remer, D. Rosenfeld, and Y. Rudich (2005), The effect of smoke, dust, and pollution aerosol on shallow cloud development over the Atlantic Ocean, P Natl. A. Sci., 102, 11,207-11,212, doi:10.1073/pnas.0505191102.

Kaufman, Y. J., and I. Koren (2006), Smoke and pollution aerosol effect on cloud cover, Science, 313, 655-658, doi:10.1126/science.1126232.

Kinne, S., D. O'Donnel, P. Stier, S. Kloster, K. Zhang, H. Schmidt, S. Rast, M. Giorgetta, T. F. Eck, and B. Stevens (2013), MAC-v1: A new global aerosol climatology for climate studies, J. Adv. Model. Earth Syst., 5(4), 704-740, doi:10.1002/jame.20035.

Klein, S., and D. Hartmann (1993), The seasonal cycle of low stratiform clouds, J. Clim., 6, 1587-1606, doi:10.1175/1520-0442(1993)006<1587:TSCOLS>2.0.CO;2.

Koren, I., Y. Kaufman, D. Rosenfeld, L. Remer, and Y. Rudich (2005), Aerosol invigoration and restructuring of Atlantic convective clouds, Geophys. Res. Lett., 32, L14828, doi:10.1029/2005GL023187.

Koren, I., J. Martins, L. A. Remer, and H. Afargan (2008), Smoke invigoration versus inhibition of clouds over the Amazon, Science, 321, 946-949, doi:10.1126/science.1159185.

Koren, I., G. Feingold, and L. Remer (2010a), The invigoration of deep convective clouds over the Atlantic: Aerosol effect, meteorology or retrieval artifact?, Atmos. Chem. Phys., 10, 8855-8872, doi:10.5194/acp-10-8855-2010.

Koren, I., L. Remer, O. Altaratz, J. Martins, and A. Davidi (2010b), Aerosol-induced changes of convective cloud anvils produce strong climate warming, Atmos. Chem. Phys., 10, 5001-5010, doi:10.5194/acp-10-5001-2010.

Koren, I., O. Altaratz, L. A. Remer, G. Feingold, J. V. Martins, and R. H. Heiblum (2012), Aerosol-induced intensification of rain from the tropics to the mid-latitudes, Nature Geosci., 5, 118-122, doi:10.1038/ngeo1364.

Lebsock, M., G. Stephens, and C. Kummerow (2008), Multisensor satellite observations of aerosol effects on warm clouds, J. Geophys. Res., 113, D15205, doi:10.1029/2008JD009876.

Lehahn, Y., I. Koren, O. Altaratz, and A. B. Kostinski (2011), Effect of coarse marine aerosols on stratocumulus clouds, Geophys. Res. Lett., 38, L20804, doi:10.1029/2011GL048504.

Levy, R. C., S. Mattoo, L. A. Munchak, L. A. Remer, A. M. Sayer, F. Patadia, and N. C. Hsu (2013), The Collection 6 MODIS aerosol products over land and ocean, Atmos. Meas. Tech., 6, 2989-3034, doi:10.5194/amt-6-2989-2013.

Liu, J., and Z. Li (2014), Estimation of cloud condensation nuclei concentration from aerosol optical quantities: Influential factors and uncertainties, Atmos. Chem. Phys., 14, 471-483, doi:10.5194/acp-14-471-2014.

Loeb, N. G., and G. L. Schuster (2008), An observational study of the relationship between cloud, aerosol and meteorology in broken low-level cloud conditions, J. Geophys. Res., 113, D14214, doi:10.1029/2007JD009763.

Mauger, G., and J. Norris (2007), Meteorological bias in satellite estimates of aerosol-cloud relationships, Geophys. Rev. Lett., 34, D16824, doi:10.1029/2007GL029952.

McComiskey, A., and G. Feingold (2012), The scale problem in quantifying aerosol indirect effects, Atmos. Chem. Phys., 12, 1031-1049, doi:10.5194/acp-12-1031-2012.

Medeiros, B., and B. Stevens (2011), Revealing differences in GCM representations of low clouds, Clim. Dyn., 36, 385-399, doi:10.1007/s00382-009-0694-5.

Merk, D., H. Deneke, B. Pospichal, and P. Seifert (2015), Investigation of the adiabatic assumption for estimating cloud micro- and macrophysical properties from satellite and ground, Atmos. Chem. Phys., 15(4), 5129-5173, doi:10.5194/acpd-15-5129-2015.

Meskhidze, N., L. Remer, S. Platnick, R. Negron Juarez, A. LichtenBerger, and A. Aiyyer (2009), Exploring the differences in cloud properties observed by the Terra and Aqua MODIS sensors, Atmos. Chem. Phys., 9, 3461-3475, doi:10.5194/acp-9-3461-2009.

Morcrette, J.-J., A. Benedetti, L. Jones, J. Kaiser, M. Razinger, and M. Suttie (2011), Prognostic aerosols in the ECMWF IFS: MACC vs GEMS aerosols, Tech. Rep., ECMWF, Reading, U. K.

Nakajima, T., and M. D. King (1990), Determination of the optical thickness and effective particle radius of clouds from reflected solar radiation measurements. Part I: Theory, J. Atmos. Sci., 47(15), 1878-1893, doi:10.1175/1520-0469(1990)047<1878:DOTOTA>2.0.CO;2.

Nam, C., S. Bony, J.-L. Dufresne, and H. Chepfer (2012), The 'too few, too bright' tropical low-cloud problem in CMIP5 models, Geophys. Res. Lett., 39(21), L21801, doi:10.1029/2012GL053421.

Pearl, J. (1994), A probabilistic calculus of actions, in Uncertainty in Artificial Intelligence, vol. 10, edited by R. Lopez de Mantaras and D. Poole, pp. 454-462, Morgan Kaufmann, San Mateo, Calif., doi:10.1016/B978-1-55860-332-5.50062-6

Penner, J. E., L. Xu, and M. Wang (2011), Satellite methods underestimate indirect climate forcing by aerosols, Proc. Natl. Acad. Sci. U.S.A., 108, 13,404-13,408, doi:10.1073/pnas.1018526108.

Platnick, S., M. King, S. Ackerman, W. Menzel, B. Baum, J. Riedi, and R. Frey (2003), The MODIS cloud products: Algorithms and examples from Terra, IEEE T. GeoSci. Remote, 41, 459-473, doi:10.1109/TGRS.2002.808301.

Quaas, J., O. Boucher, and U. Lohmann (2006), Constraining the total aerosol indirect effect in the LMDZ and ECHAM4 GCMs using MODIS satellite data, Atmos. Chem. Phys., 6, 947-955, doi:10.5194/acp-6-947-2006.

Quaas, J., O. Boucher, N. Bellouin, and S. Kinne (2008), Satellite-based estimate of the direct and indirect aerosol climate forcing, J. Geophys. Res., 113, D05204, doi:10.1029/2007JD008962.

Quaas, J., et al. (2009), Aerosol indirect effects - General circulation model intercomparison and evaluation with satellite data, Atmos. Chem. Phys., 9, 8697-8717, doi:10.5194/acp-9-8697-2009. 
Quaas, J., B. Stevens, P. Stier, and U. Lohmann (2010), Interpreting the cloud cover-aerosol optical depth relationship found in satellite data using a general circulation model, Atmos. Chem. Phys., 10, 6129-6135, doi:10.5194/acp-10-6129-2010.

Rosenfeld, D., Y. Rudich, and R. Lahav (2001), Desert dust suppressing precipitation: A possible desertification feedback loop, Proc. Natl. Acad. Sci. U.S.A., 98, 5975-5980, doi:10.1073/pnas.101122798.

Seifert, A., T. Heus, R. Pincus, and B. Stevens (2015), Large-eddy simulation of the transient and near-equilibrium behavior of precipitating shallow convection, J. Adv. Mod. Earth Sys., 7, 1918-1937, doi:10.1002/2015MS000489.

Sekiguchi, M., T. Nakajima, K. Suzuki, K. Kawamoto, A. Higurashi, D. Rosenfeld, I. Sano, and S. Mukai (2003), A study of the direct and indirect effects of aerosols using global satellite data sets of aerosol and cloud parameters, J. Geophys. Res., 108, 4699, doi:10.1029/2002JD003359.

Shinozuka, Y., et al. (2015), The relationship between cloud condensation nuclei (CCN) concentration and light extinction of dried particles: Indications of underlying aerosol processes and implications for satellite-based CCN estimates, Atmos. Chem. Phys., 15, 7585-7604, doi:10.5194/acp-15-7585-2015.

Small, J. D., P. Y. Chuang, G. Feingold, and H. Jiang (2009), Can aerosol decrease cloud lifetime?, Geophys. Res. Lett., 36, L16806, doi:10.1029/2009GL038888.

Small, J. D., J. H. Jiang, H. Su, and C. Zhai (2011), Relationship between aerosol and cloud fraction over Australia, Geophys. Res. Lett., 38, L23802, doi:10.1029/2011GL049404.

Stevens, B. (2015), Rethinking the lower bound on aerosol radiative forcing, J. Clim., 28(12), 4794-4819, doi:10.1175/JCLI-D-14-00656.1.

Stevens, B., and A. Seifert (2008), Understanding macrophysical outcomes of microphysical choices in simulations of shallow cumulus convection, J. Met. Soc. Japan, 86A(8), 143-162, doi:10.2151/jmsj.86A.143.

Swap, R. J. (2003), Africa burning: A thematic analysis of the Southern African Regional Science Initiative (SAFARI 2000), J. Geophys. Res., 108, 8465, doi:10.1029/2003JD003747.

Tao, W.-K., J.-P. Chen, Z. Li, C. Wang, and C. Zhang (2012), Impact of aerosols on convective clouds and precipitation, Rev. Geophys., 50 , RG2001, doi:10.1029/2011RG000369.

Twomey, S. (1977), The influence of pollution on the shortwave albedo of clouds, J. Atmos. Sci., 34, 1149-1152, doi:10.1175/1520-0469(1977)034<1149:TIOPOT>2.0.CO;2.

Várnai, T., and A. Marshak (2009), Modis observations of enhanced clear sky reflectance near clouds, Geophys. Res. Lett., 36, L06807, doi:10.1029/2008GL037089.

Várnai, T., and A. Marshak (2011), Global CALIPSO observations of aerosol changes near clouds, IEEE Geosci. Remote Sens. Lett., 8(1), 19-23, doi:10.1109/LGRS.2010.2049982.

Wielicki, B. A., B. R. Barkstrom, E. F. Harrison, R. B. Lee, G. Louis Smith, and J. E. Cooper (1996), Clouds and the Earth's Radiant Energy System (ceres): An Earth observing system experiment, Bull. Am. Met. Soc., 77(5), 853-868, doi:10.1175/1520-0477(1996)077<0853:CATERE> 2.0.CO;2.

Xue, H., and G. Feingold (2006), Large-eddy simulations of trade wind cumuli: Investigation of aerosol indirect effects, J. Atmos. Sci., 63, 1605-1622, doi:10.1175/JAS3706.1.

Yuan, T., Z. Li, R. Zhang, and J. Fan (2008), Increase of cloud droplet size with aerosol optical depth: An observation and modeling study, J. Geophys. Res., 113, D04201, doi:10.1029/2007JD008632.

Yuan, T., L. Remer, and H. Yu (2011), Microphysical, macrophysical and radiative signatures of volcanic aerosols in trade wind cumulus observed by the A-train, Atmos. Chem. Phys., 11, 7119-7132, doi:10.5194/acp-11-7119-2011.

Zelinka, M. D., T. Andrews, P. M. Forster, and K. E. Taylor (2014), Quantifying components of aerosol-cloud-radiation interactions in climate models, J. Geophys. Res. Atmos., 119, 7599-7615, doi:10.1002/2014JD021710.

Zhang, J., J. Reid, and B. Holben (2005), An analysis of potential cloud artifacts in MODIS over ocean aerosol optical thickness products, Geophys. Res. Lett., 32, L15803, doi:10.1029/2005GL023254.

Zhang, Z., and S. Platnick (2011), An assessment of differences between cloud effective particle radius retrievals for marine water clouds from three MODIS spectral bands, J. Geophys. Res., 116, D20215, doi:10.1029/2011JD016216.

Zuidema, P., and D. Painemal (2009), Stratocumulus cloud-top height estimates and their climatic implications, J. Clim., 22, 4652-4666, doi:10.1175/2009JCLI2708.1. 